

\section{DISCLAIMER}

This report was prepared as an account of work sponsored by an agency of the United States Government. Neither the United States Government nor any agency Thereof, nor any of their employees, makes any warranty, express or implied, or assumes any legal liability or responsibility for the accuracy, completeness, or usefulness of any information, apparatus, product, or process disclosed, or represents that its use would not infringe privately owned rights. Reference herein to any specific commercial product, process, or service by trade name, trademark, manufacturer, or otherwise does not necessarily constitute or imply its endorsement, recommendation, or favoring by the United States Government or any agency thereof. The views and opinions of authors expressed herein do not necessarily state or reflect those of the United States Government or any agency thereof. 


\section{DISCLAIMER}

Portions of this document may be illegible in electronic image products. Images are produced from the best available original document. 


\title{
RECENT RESULTS FROM STUDIES \\ OF NON-GASEOUS FISSION PRODUCTS \\ WITH TRISTAN II
}

John C. Hill

\author{
Ames Laboratory, USDOE \\ Iowa State University \\ Ames, Iowa 50011
}

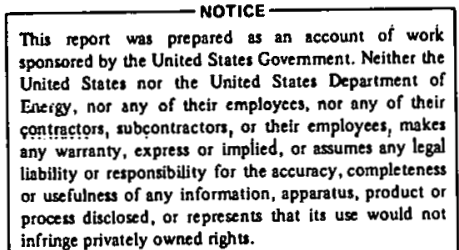

process disclosed, or represents that its use product or

infringe privately owned rights.

-

Date Transmitted: March 1978

PREPARED FOR THE U.S. DEPARTMENT OF ENERGY

UNDER CONTRACT NO. W-7405-eng-82 


\section{NOTICE}

This report was prepared as an account of work sponsored by the United States Government. Neither the United States nor the United States Department of Energy, nor any of their employees, nor any of their cuntractors, subcontractors, or their employees, makes any warranty, cxpress or implied, on assiumes any legal liability or responsibility for the accuracy, completeness, or usefulness of any information, apparatus, product or process disclosed, or represents that its use would not infringe privately owhed rights.

Available from: National Technical Information Service

U. S. Department of Commerce

P.O. Bux 1500

Springfield, VA 22161

Price: Micr ofiche 
TABLE OF CONTENTS

l.ipe

Abstract iv

1. Introduction 1

2. Survey Results for Non-Gaseous Fission Products 1

3. Studies of Neutron-Rich Even-Even Cd Nuclei 10

3.1 Decay of ${ }^{118} \mathrm{Ag}$ to Levels in ${ }^{118} \mathrm{Cd} \quad 11$

3.2 Decay of ${ }^{122} \mathrm{Ag}$ to Levels in ${ }^{122} \mathrm{Cd} \quad 18$

3.3 Systematics for Even-Even Cd Nuclei 25

4. Studies in the Tin Region at TRISTAN II. 27

4.1 Structure of ${ }^{126} \mathrm{Sn}$ and ${ }^{128} \mathrm{Sn}$ from the Decay of.

$\begin{array}{ll}\text { In Fission Products } & 27\end{array}$

4.2 The Decay of ${ }^{126} \mathrm{Cd}$. 29

5. Possibilities for Future Studies at TRISTAN II 34

5.1 The Region Near Doubly-Magic ${ }^{78}{ }_{\mathrm{Ni}}$

5.2 The Doubly-Magic ${ }^{132}$ Sn Region 36

$\begin{array}{lll}\text { Acknowledgments } & 39\end{array}$

$\begin{array}{ll}\text { References } & 41\end{array}$

Distribution List 43 


\begin{abstract}
A new in-beam target ion-source combination has been installed at the TRISTAN isotope separator facility. Mass separated beams of nongaseous fission products are now available for study. Studies of levels in even-even $C d$ and $S n$ nuclei populated through the decay of $\mathrm{Ag}$ and In fisston products are described, and an evaluation of possibilities for future research is made.
\end{abstract}




\section{Introduction}

The TRISTAN isotope separator facility located at the Ames Laboratory Research Reactor has been used for many years to study the properties of the fission-product nuclei $\mathrm{Kr}$ and $\mathrm{Xe}$ and their daughters. A description of the capabilities and accomplishments of this facility has been given by Talbert ${ }^{1}$. Although a large number of comprehensive studies were carried out, the system was limited by the inability to study fission products other than the rare gases and their daughters.

The above situation changed in the Summer of 1976 due to the successful operation of a new in-beam target ion-source combination of the type used at the OSIRIS separator ${ }^{2}$. The new ion-source allowed us to ionize and mass separate beams of $\mathrm{Zn}, \mathrm{Ga}, \mathrm{Br}, \mathrm{Kr}, \mathrm{Rb}, \mathrm{Ag}, \mathrm{Cd}$, In, $\mathrm{Sn}, \mathrm{Sb}, \mathrm{Te}, \mathrm{I}, \mathrm{Xe}$, and Cs. It will also probably be possible to separate Ge, As, Se, Sr, and Ba. The new system was christened TRISTAN II and its capabilities are described by $W^{3} n^{3}$. In sections 2,3 , and 4 , results from the first year of operation of TRISTAN II are described, and in section 5 a discussion of the future possibilities for nuclear structure research is given.

\section{Survey Results for Non-Gaseous Fission Products}

Soon after the successful installation of the new ion-source a $4 \pi$ survey of fission-product activity as a function of mass number was carried out. (The rcsults of the survey are shown in F1g. 1.) The details of this measurement are described by $W^{3}{ }^{3}$ but it is useful here to discuss some of the principal features. The small peak near mass 78 represents production from our ion source of beams of $\mathrm{Zn}$ and $\mathrm{Ga}$ fission products. A $\gamma$ ray survey run was made at mass 78 using a $15 \%$ efficient $\mathrm{Ge}(\mathrm{Li})$. detector. The $\mathrm{A}=78$ beam 


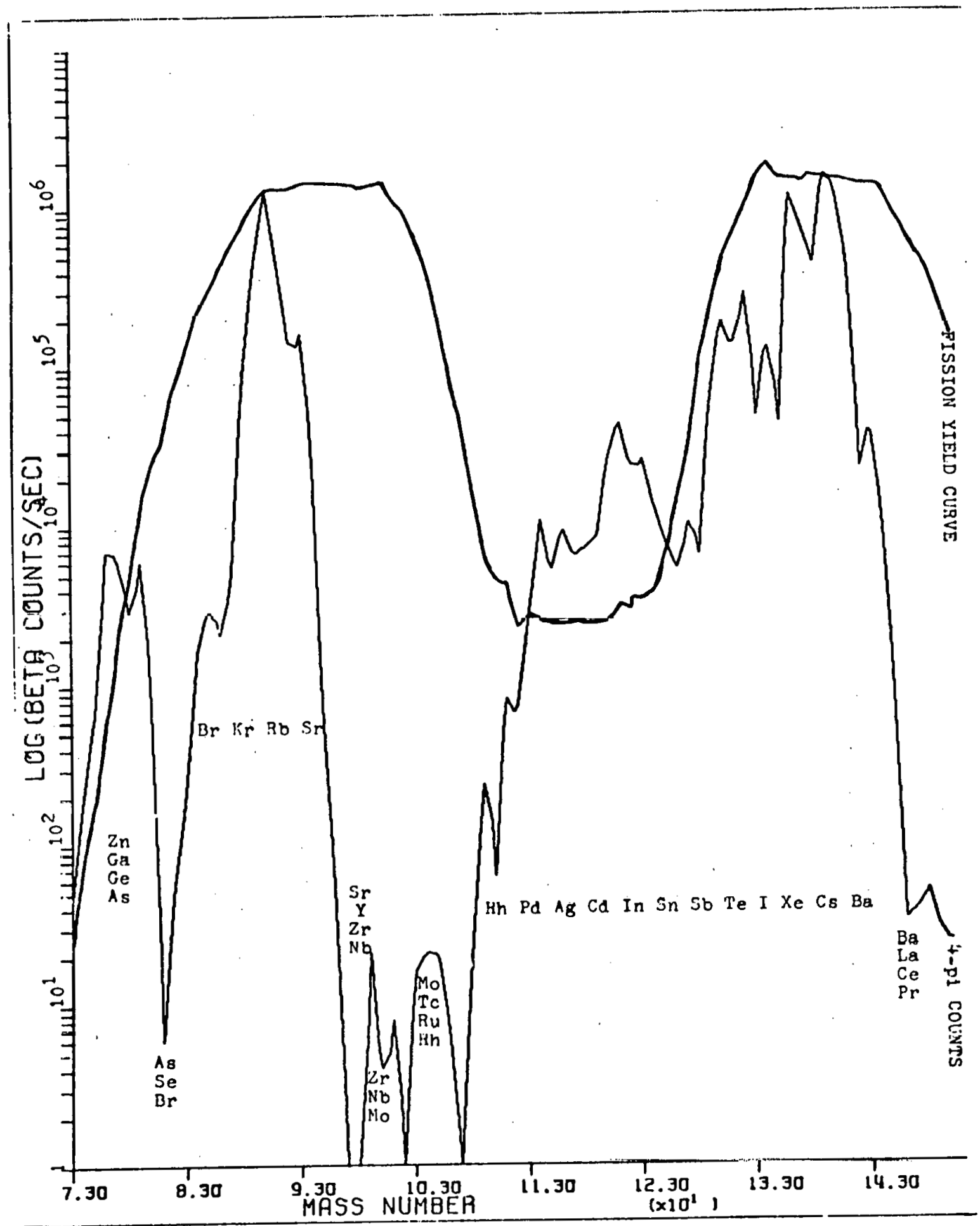

Fig. 1: Mass scan of fission-product activity obtained with $4 \pi \beta$ counting at TRISTAN II. The mass distribution for thermal neutron fission of $235_{U}$ is included for reference. 
was collected on the tape of the moving tape collector (MTC). The tape was moved every $3 \mathrm{sec}$. to enhance the short-lived ${ }^{78} \mathrm{Zn}\left(\mathrm{T}_{1 / 2}=1.5 \mathrm{sec}\right.$.) and ${ }^{78}{ }_{\mathrm{Ga}}\left(\mathrm{T}_{1 / 2}=5\right.$ sec. $)$ activities. A spectrum accumulated in a $15 \mathrm{~min}$. run is shown in Fig. 2. It is evident from the figure that sufficient activity is available to carry out detailed spectroscopic studies on the above activities and that holdup times in the ion source for $\mathrm{Zn}$ and $\mathrm{Ga}$ are short.

$A \gamma$ ray survey run was also made at $A=86$ to determine the availability of $\mathrm{Br}$ activities from TRISTAN II. The $\mathrm{A}=86$ beam was collected on the tape of the MTC and counting was done in equilibrium since the ${ }^{86} \mathrm{Kr}$ daughter of ${ }^{86} \mathrm{Br}\left(\mathrm{T}_{1 / 2}=55 \mathrm{sec}.\right)$ is stable. A spectrum accumulated in a $20 \mathrm{~min}$. run is shown in Fig. 3. Yields of $\mathrm{Br}$ isotopes appear to be sufficient for decay studies.

The peak in the $4 \pi$ survey. at about $A=90$ results from the high yields out of our ion source of $\mathrm{Kr}$ and $\mathrm{Rb}$. Studies of $\mathrm{Kr}$ and $\mathrm{Xe}$ fission products have been carried out in great detail at TRISTAN $I$ and studies of $\mathrm{Rb}$ and $\mathrm{Cs}$ are being made at several different ISOL facilities using surface-ionization ion sources, therefore the emphasis in the TRISTAN II program should not be on these elements. Nevertheless a $\gamma$ ray survey was máde at $A=96$. Large quantitles of ${ }^{96} \mathrm{Rb}\left(\mathrm{T}_{1 / 2}=0.2 \mathrm{sec}\right.$.) were observed indicating an extremely short holdup time for $\mathrm{Rb}$ in. our ion source. The deep valley in our $4 \pi$ yield curve running from $A=98$ to $A=111$ is caused by the onset in the periodic table of a series of refractory elements ranging from $Y(Z=39)$ to $\operatorname{Pd}(Z=46)$. These elements are not volatized in our ion source but can be studied in systems ${ }^{4}$ Iike LOHENGRIN and JOSEF where the fission fragments are directly mass analyzed. 


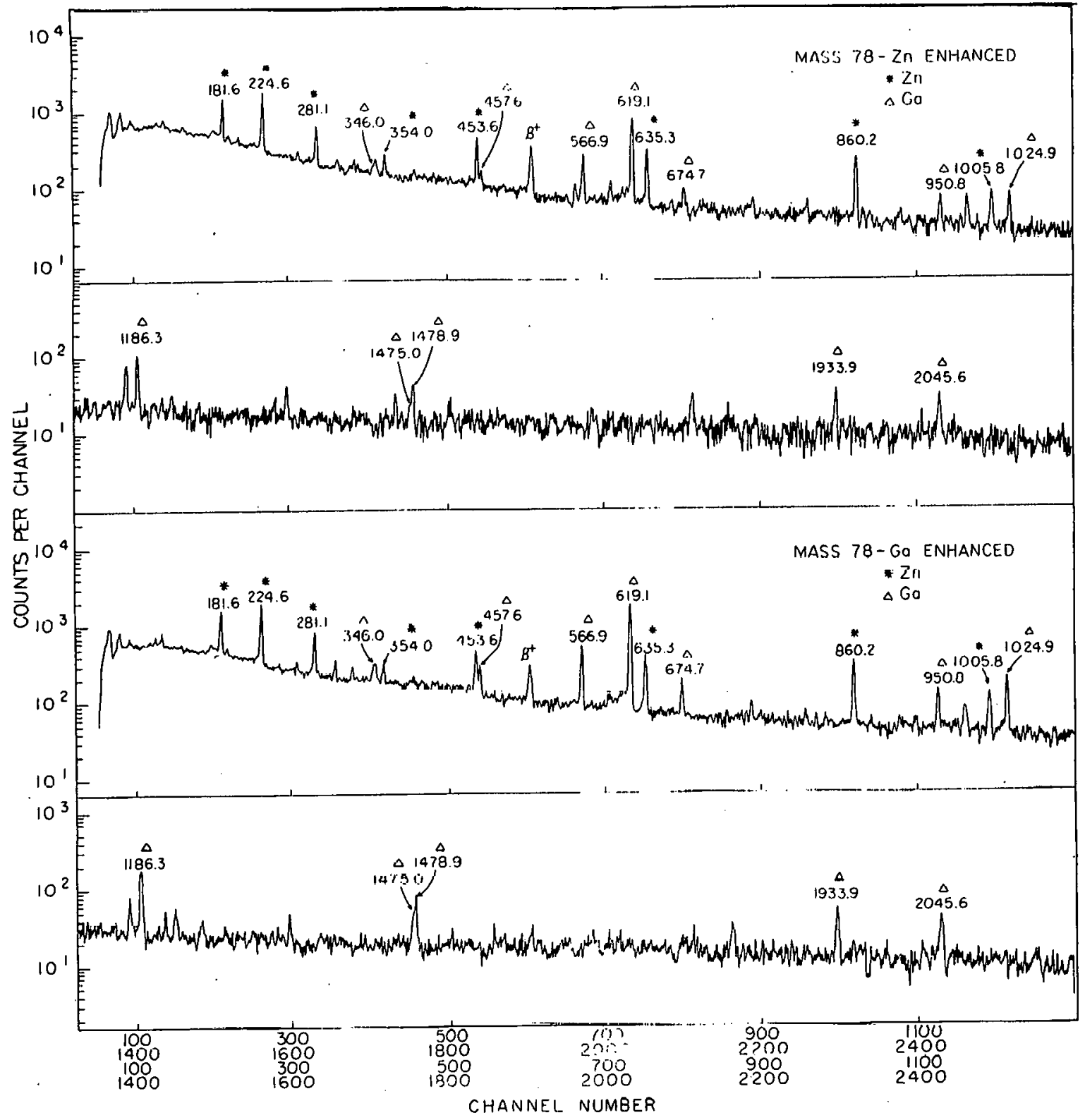

F1g. 2: Gamma spectrum from survey run at $A=78$. Run time was $15 \mathrm{~min}$. 


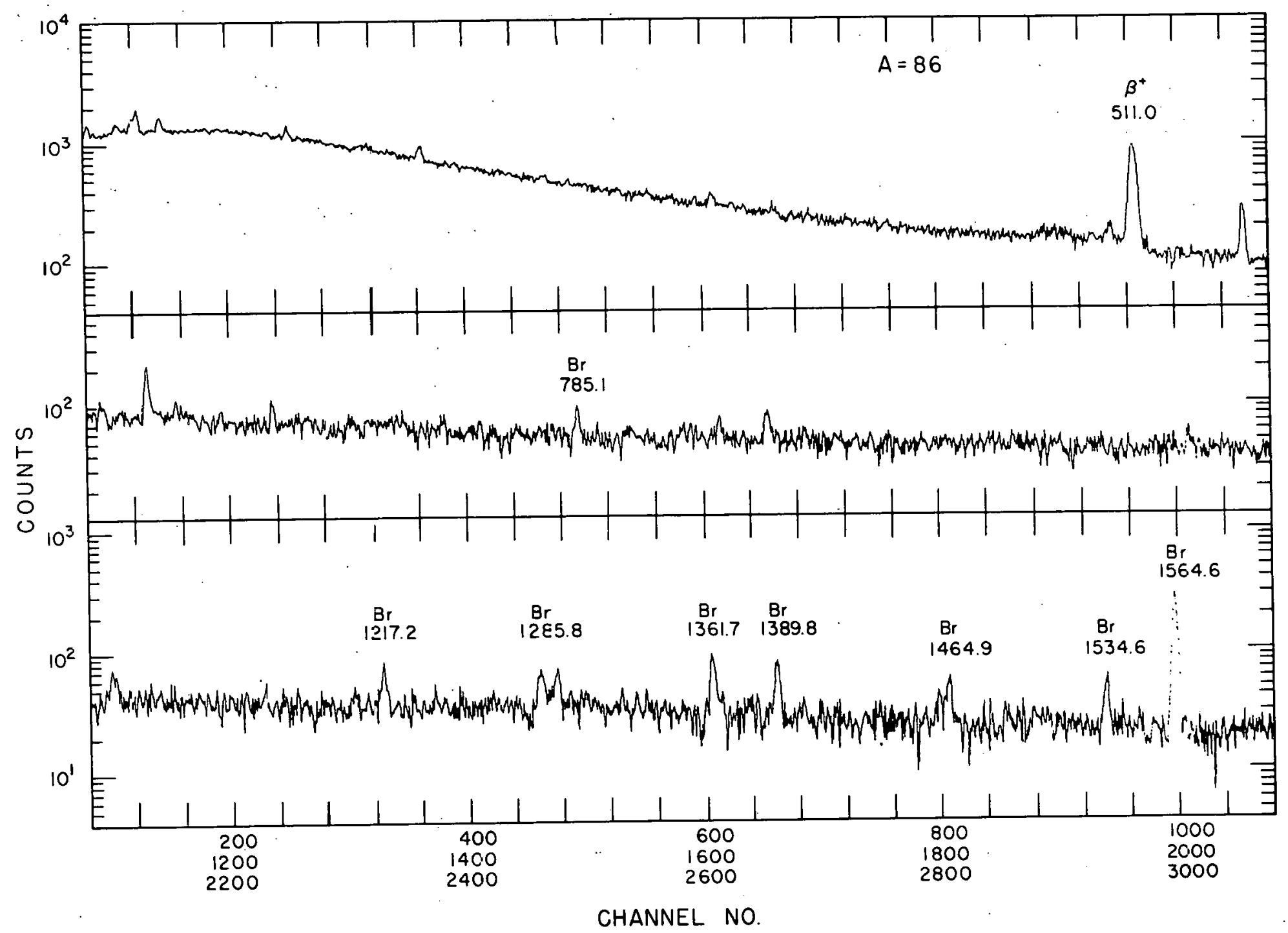

Fig. 3: Gamma spectrum from survey run at $A=86$. Run time was $20 \mathrm{~min}$. 
A very important plateau in the $4 \pi$ yield curve occurs between $A=114$ and $\mathrm{A}=129$. This plateau results from high yields of $\mathrm{Ag}, \mathrm{Cd}$, and In fission products from our ion source. Spectroscopic studies at TRISTAN II in the first year have concentrated on decay characteristics of even A nuclei in this region. Representative $\gamma$ spectra obtained during studies of the decay of ${ }^{118} \mathrm{Ag}$ and ${ }^{122} \mathrm{Ag}$ are presented in section 3. A $\gamma$ spectrum obtained at $A=126$ is shown in Fig. 4. The tape on the moving tape collector was moved every $5 \mathrm{sec}$, to enhance activities from ${ }^{126} \mathrm{Cd}\left(\mathrm{T}_{1 / 2}=0.5 \mathrm{sec}\right.$.) and ${ }^{126} \operatorname{In}\left(\mathrm{T}_{1 / 2}\right.$ $=1.6 \mathrm{sec}$.$) . Yields of \mathrm{Ag}, \mathrm{Cd}$, and In fission products are sufficient for detailed spectroscopic studies of nuclet even though these elements are in the valley of the fission mass-yield curve. Also successful studies of short-iived isotopes such as ${ }^{120} \mathrm{Ag}\left(\mathrm{T}_{1 / 2}=0.3 \mathrm{sec}.\right),{ }^{126} \mathrm{Cd}\left(\mathrm{T}_{1 / 2}=0.5 \mathrm{sec}.\right)$, and ${ }^{128} \operatorname{In}\left(\mathrm{T}_{1 / 2}=0.8 \mathrm{sec},\right)$ indicate that the holdup time for these elements in the TRISTAN II ion source is quite short.

The second major peak in the $4 \pi$ mass yield curve starts at about $A=130$ and continues to about $\mathrm{A}=144$. The fission products $\mathrm{I}, \mathrm{Xe}$, and $\mathrm{Cs}$ are the major contributors to this peak but significant quantities of $\mathrm{Sn}, \mathrm{Sb}$, and $\mathrm{Te}$ are also produced. A 15 min. $\gamma$ spectrum at $A=130$ taken under equilibrium conditions at our MTC is shown in Fig. 5. Peaks from $\gamma$ rays emitted in the decay of ${ }^{130} \mathrm{Sn}\left(\mathrm{T}_{1 / 2}=3.7 \mathrm{~min}.\right),{ }^{130} \mathrm{Sb}\left(\mathrm{T}_{1 / 2}=37 \mathrm{~min}.\right)$, and ${ }^{130} \mathrm{Sb}^{*}\left(\mathrm{~T}_{1 / 2}=\right.$ 6.6 min.) are clearly evident. In fig. 0 a 15 min. $\gamma$ spectrum taken in equilibrium at $\mathrm{A}=134$ is presented. Most of the $\gamma$ strength is from the decay of ${ }^{134} \mathrm{I}_{\left(\mathrm{T}_{1 / 2}\right.}=53 \mathrm{~min}$.) but significant activity from ${ }^{134} \mathrm{Te}\left(\mathrm{T}_{1 / 2}=\right.$ 42 min.) is also observed. It is evident from Fig. 6 that large yields of I are produced from the TRISTAN II ion source. Although neutron-rich I 


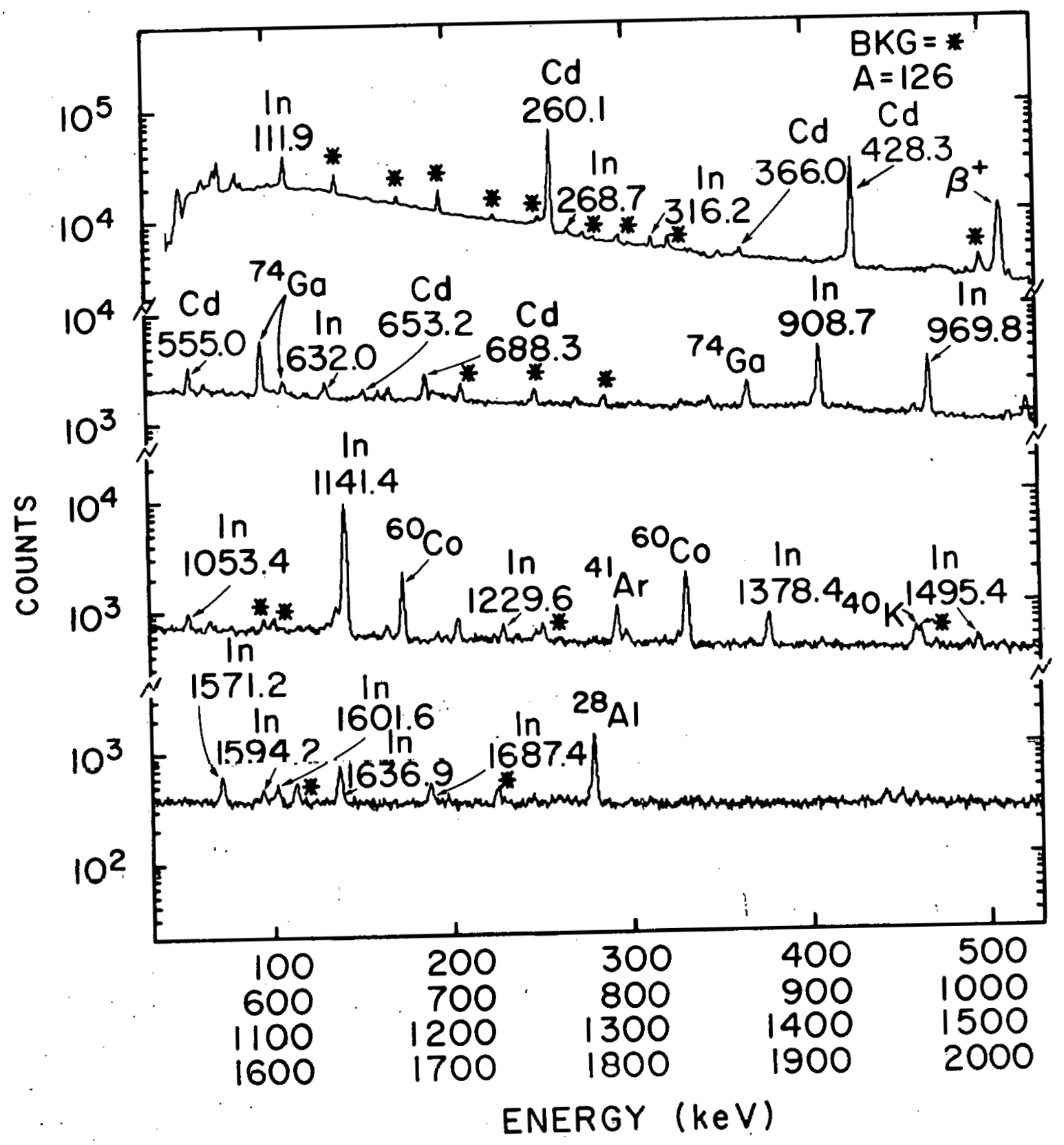

Fig. 4: Gamma spectrum obtalned in study of $126 \mathrm{Cd}$ and $126 \mathrm{In}$ decay. Run time was 20 hours. 


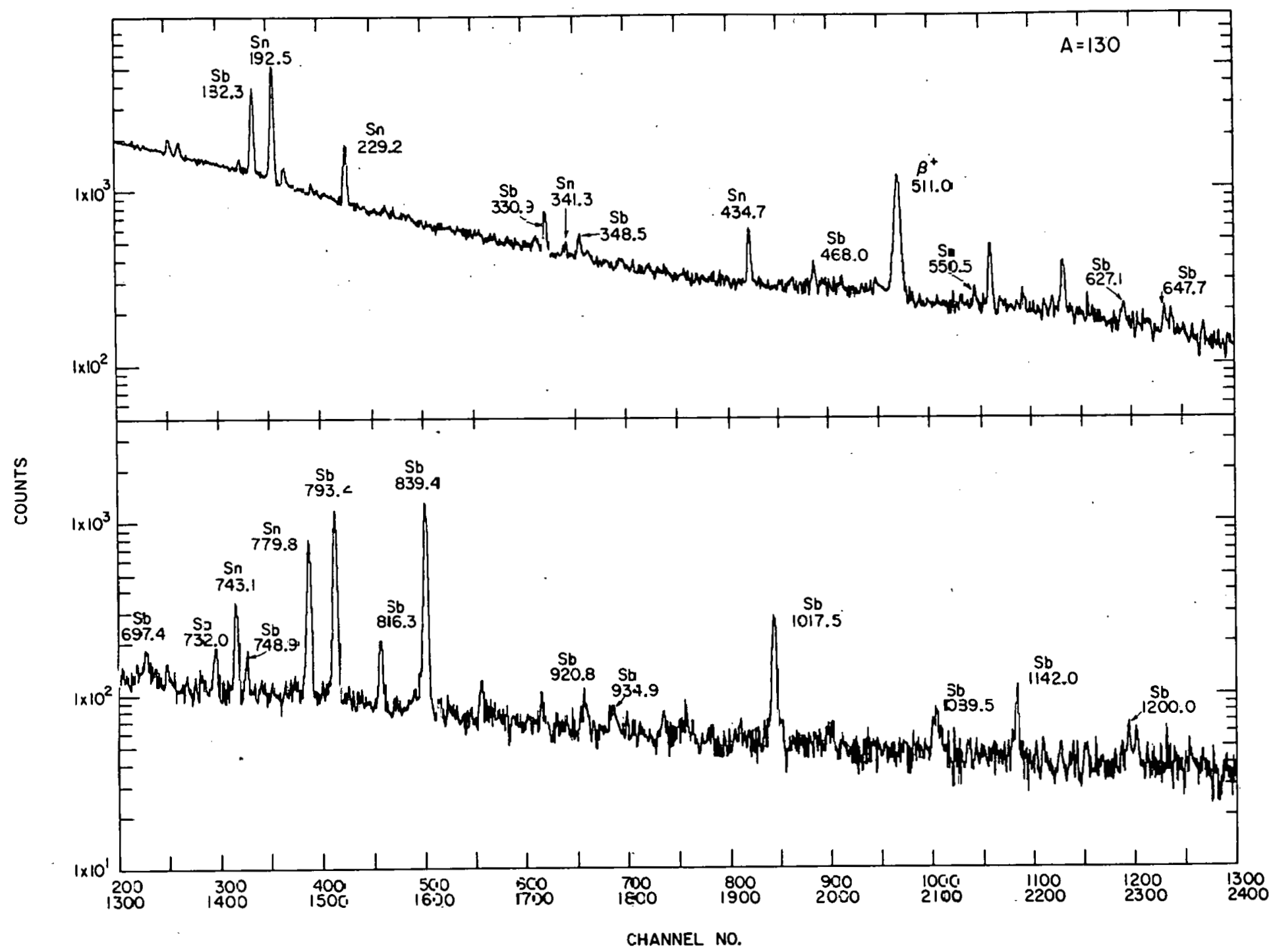

$\infty$

Fig. 5: Gamma spectrum from survey run at A = 130. Rin time was 15 min. 


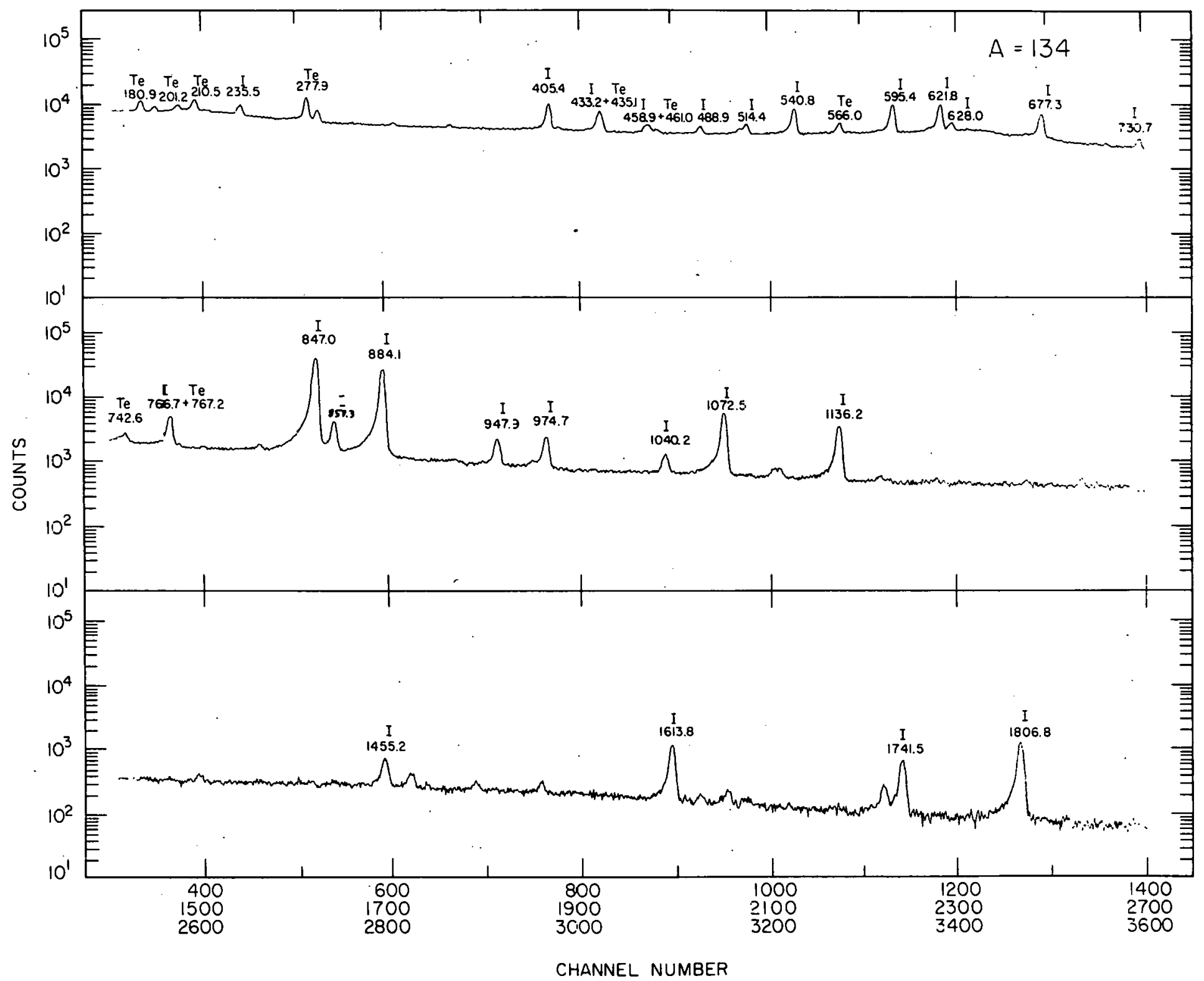

Fig. 6: Gama spectrum from survey run at $A=134$. Run time was 15 min. 
isotopes have been observed up to ${ }^{141} I$, no structure information is available from I decays on mass numbers greater than 136 except for a recent study of ${ }^{138}$ I decay ${ }^{5}$. This area is certainly appropriate for future studies. Figures 5 and 6 illustrate the production of $\mathrm{Sn}, \mathrm{Sb}, \mathrm{Te}$, and I at TRISTAN II but holdup times in our ion source for elements like $\mathrm{Sn}, \mathrm{Sb}$, and $\mathrm{Te}$ may be somewhat longer than for elements like $\mathrm{Ag}, \mathrm{Cd}$, and In. Future surveys will he needed to study this problem. If detailed decay studies of short-lived $\mathrm{Sn}, \mathrm{Sb}$, and $\mathrm{Te}$ can be carried out, much new information on the very interesting region near doubly-magic ${ }^{132}$ Sn can be obtained.

\section{Studies of Neutron-Rich Even-Even Cd Nuclei}

Soon after the successful operation of the in-beam ion source, a series of experiments was started with the object of studying the detailed level structures of neutron-rich even-even Cd nuclei populated in the $\beta$ decay of Ag fission products. Earlier in this paper, we pointed out that the yield of $\mathrm{Ag}$ from our ion source was high even though $\mathrm{Ag}$ is at the bottom of the valley of the fission mass-yield curve. Also the holdup time for Ag in our ion source was seen to be short as evidenced by observation in good yields of the short-lived isomer of ${ }^{120} \mathrm{Ag}\left(\mathrm{T}_{1 / 2}=0.3 \mathrm{sec}.\right)$, thus $i t$ was possible to observe $\mathrm{Ag}$ nuclei out to ${ }^{122} \mathrm{Ag}$. Studies of the decays of ${ }^{110} \mathrm{Ag}$ and ${ }^{120} \mathrm{Ag}$ are in progress ${ }^{6,7}$ and work on ${ }^{122} \mathrm{Ag}$ has been completed ${ }^{8}$.

Cd nuclei contain 48 protons which is only two less than the $Z=50$ closed shell. It was thus thought that the low-lying excltations of eveneven Cd nuclei could be described in terms of simple collective vibrations. Models of this type were unable to describe levels in even-even $\operatorname{Pd}(Z=46)$ nuclei. Hsue et al. ${ }^{9}$ developed a rotation-vibration collective model which 
correctly predicted level ordering and $\mathrm{B}(\mathrm{E} 2)$ 's for ${ }^{106} \mathrm{Pd}$ below $2.5 \mathrm{MeV}$. Hsu et al. ${ }^{10}$ have extended this model to all even-even Pd nuclei from ${ }^{102} \mathrm{Pd}$ to ${ }^{114} \mathrm{Pd}$.

It is of interest to determine if the above model can be extended to describe even-even Cd nuclei. We therefore undertook a series of detailed decay studies of $\mathrm{Ag}$ fission products in order to extend the systematics of even-even $C d$ nuclei out to $A=122$. We report below on results of studies of the decay of $\left.{ }^{118} \mathrm{Ag}_{1 / 2}=3.8 \mathrm{sec}.\right),{ }^{118} \mathrm{Ag}^{*}{ }^{*}\left(\mathrm{~T}_{1 / 2}=2.0 \mathrm{sec}.\right)$, and ${ }^{122} \mathrm{Ag}\left(\mathrm{T}_{1 / 2}\right.$ $=0.48$ sec. $)$. Studies of ${ }^{120} \mathrm{Ag}\left(\mathrm{T}_{1 / 2}=1.2 \mathrm{sec}.\right)$ and ${ }^{120} \mathrm{Ag}^{*}\left(\mathrm{~T}_{1 / 2}=0.3 \mathrm{sec}.\right)$ are also in progress. Williams ${ }^{11}$ discusses the results of his model calculations in relation to our level information on Cd nuclei.

3.1. Decay of ${ }^{118} \mathrm{Ag}$ to Levels in ${ }^{118} \mathrm{Cd}$

The existence of ${ }^{118} \mathrm{Ag}$ was first confirmed by Fritze and Griffiths ${ }^{12}$ during a search for now fission products frull ${ }^{235} \mathrm{U} . \mathrm{A} \mathrm{T}_{1 / 2}$ of $5 \mathrm{sec}$. was reported, No information on levels in ${ }^{118} \mathrm{Cd}$ was available until the work of Fogelberg et al. ${ }^{13}$ who observed two isomers of ${ }^{118} \mathrm{Ag}$ with $\mathrm{T}_{1 / 2}$ 's of $2.8 \pm 0.2$ and $3.7 \pm 0.2 \mathrm{sec}$. respectively. Eight $\gamma$ transitions were placed in a level scheme consisting of seven excited levels.

In what follows we will describe in some detail the measurements and results obtained in the study of ${ }^{118} \mathrm{Ag}$ decay. This study is a good example of how the TRISTAN II facility can be used to obtain detailed spectroscopic informatiun on short-lived non-gaseous fission products. Results from $\gamma$ singles, $\gamma \gamma$-coincidence, and $\gamma$ multispectrum scaling are described below. A 30 hour ${ }^{118} \mathrm{Ag} \gamma$ singles measurement was made using a $15 \%$ efficient Ge(Li) detcctor and a LEPS detertor whlch accumulated spectra in the energy 
ranges of $0-4 \mathrm{MeV}$ and $0-400 \mathrm{keV}$ respectively. The activity was collected on the tape of the MTC system. The tape was moved every $6 \mathrm{sec}$. to minimize activity from the Cd and In daughters. $\Lambda$ separate spectrum was taken to enhance $\mathrm{Cd}$ and In. The activity was accumulated for $120 \mathrm{sec}$. but before counting, a $30 \mathrm{sec}$. delay was introduced to eliminate ${ }^{118} \mathrm{Ag}$ activity. The ${ }^{118} \mathrm{Ag}$ singles spectrum from 70 to $3400 \mathrm{keV}$ is shown in Fig. 7 and the LEPS spectrum from 0 to $300 \mathrm{keV}$ is shown in Fig. 8. A total of $53{ }^{118} \mathrm{Ag} \gamma$ rays was observed.

The $\mathrm{T}_{1 / 2}$ 's of both ${ }^{118} \mathrm{Ag}$ isomers were measured by $\gamma$ multispectral sca1ing. A total of 16 time bins each containing 1024 channels of information were used. The resulting decay curves are shown in Fig. 9. The $T_{1 / 2}$ of the ${ }^{118} \mathrm{Ag}$ ground state was determined to be $3.76 \pm 0.15 \mathrm{sec}$. from the decay of the $488-\mathrm{keV} \gamma$ ray and the $\mathrm{T}_{1 / 2}$ of the ${ }^{118} \mathrm{Ag}$ isomeric state was determined to be $2.0 \pm 0.2 \mathrm{sec}$. from the decay of the isomeric $\gamma$ ray at $128 \mathrm{keV}$. The Isomeric state $\mathrm{T}_{1 / 2}$ is considerably less than the value of $2.8 \pm 0.2$ sec. obtained by Fogelberg et al. 13

Two Ge(L1) detectors of about $15 \%$ efficiency were 1sed in $180^{\circ}$ geometry for a 17-hour $\gamma \gamma$ coincidence study. The data were stored event-by-event in a $4 \mathrm{~K}$ by $4 \mathrm{~K}$ array for later computer sorting. Typical $\gamma$ spectra in coincidence with the $488-$ and $2778-\mathrm{keV} \gamma$ rays are shown in Fig. 10.

The results of the singles and coincidence measurements were used to construct a level scheme for ${ }^{118} \mathrm{Cd}$ which is shown in Fig. 11. Of the $53 \mathrm{\gamma}$ rays observed, 38 were placed depopulating levels in ${ }^{118} \mathrm{Cd}$ up to $3382 \mathrm{keV}$. It is difficult to determine the $\beta$ feedings from each of the two ${ }^{118} \Lambda \mathrm{g}$ isomers due to the similarity of their $\mathrm{T}_{1 / 2}$ 's, but work on this is in progress. Until this is completed it is risky to assign spins to the higher lying 


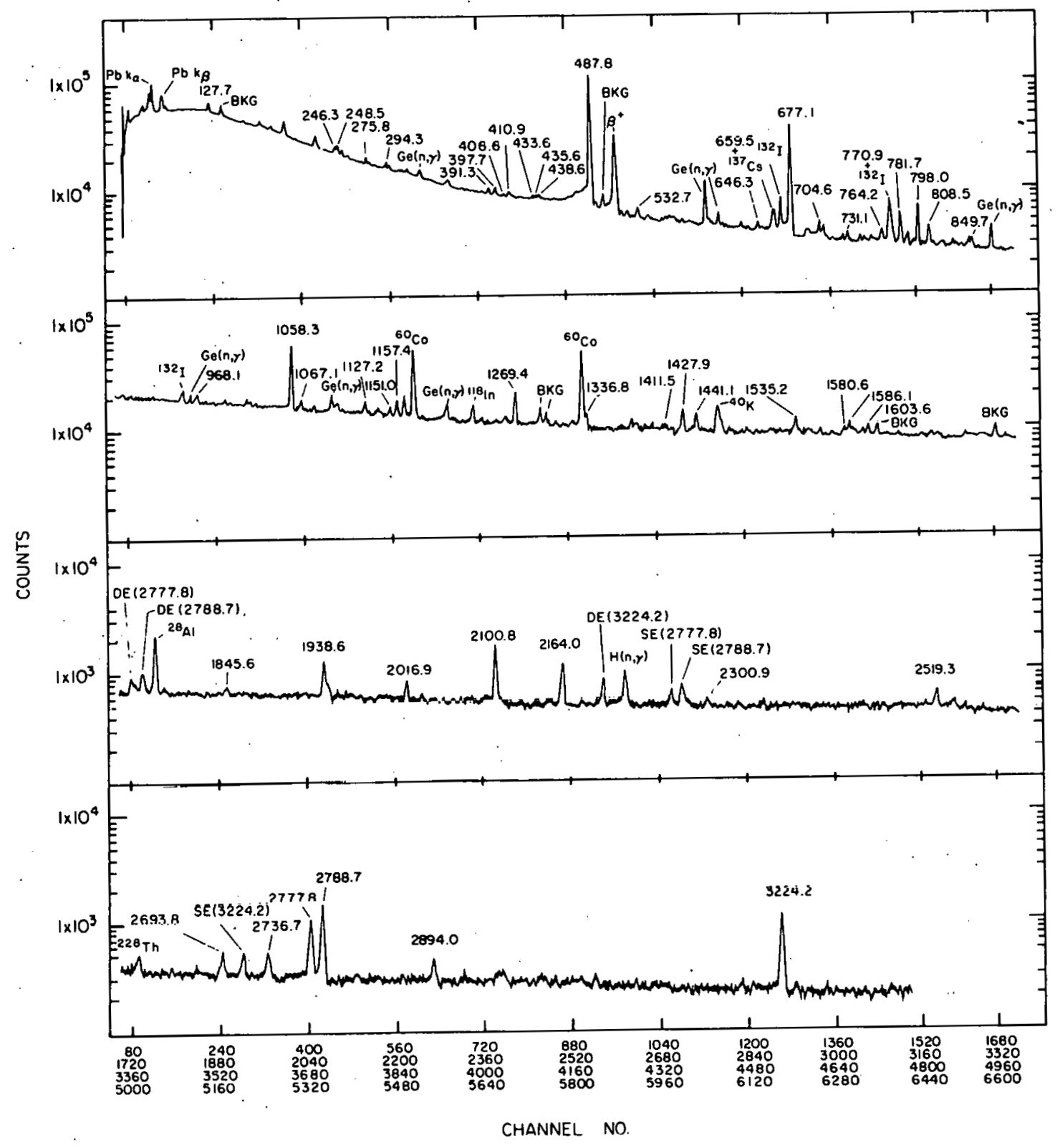

F1g. 7: Gama spectrum for $118_{\mathrm{Ag}}$ decay between 70 and $3400 \mathrm{keV}$. 


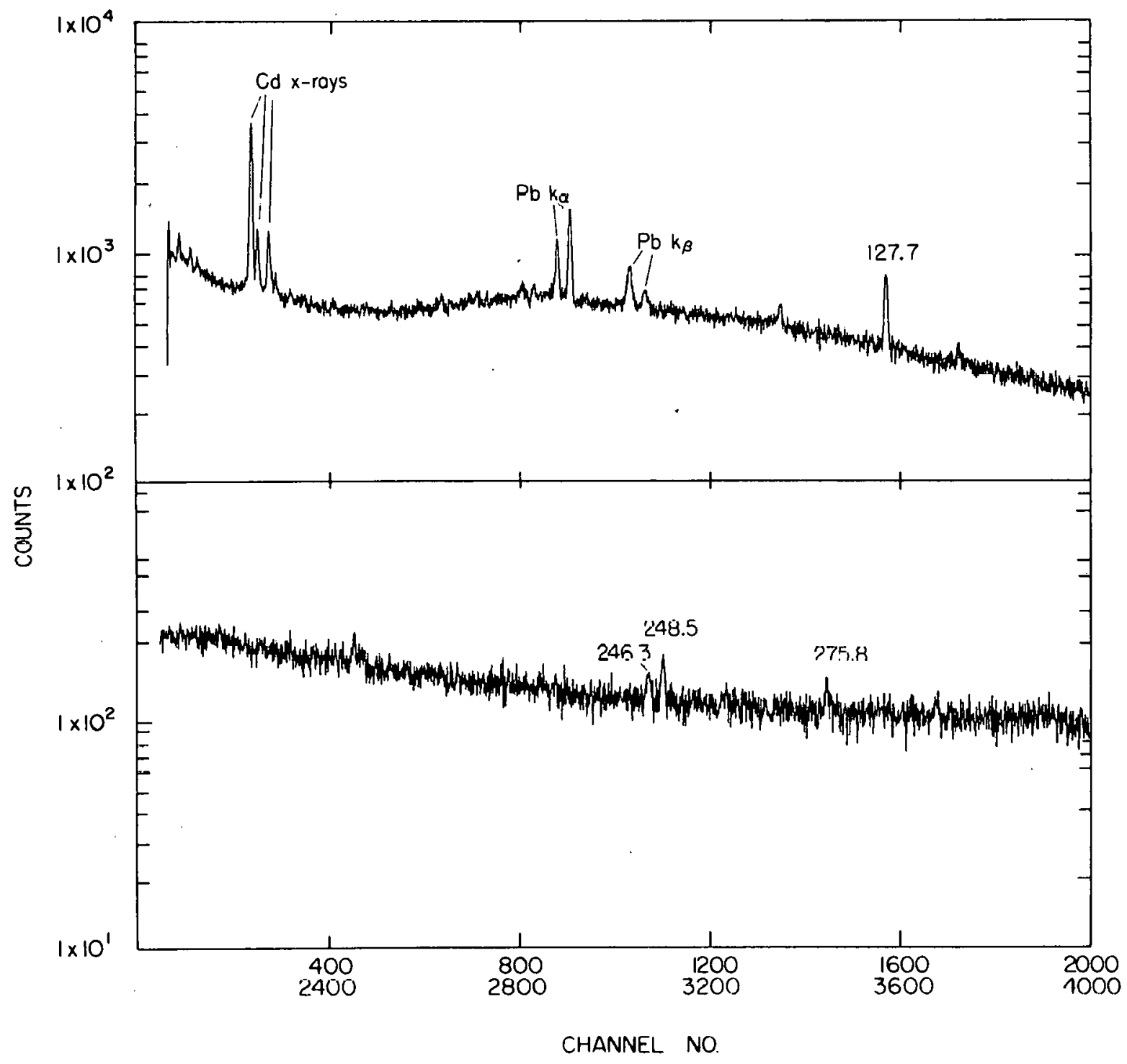

F1g. 8: LEPS spectrum for $118_{\mathrm{Ag}}$ decay between 0 and $300 \mathrm{keV}$. 


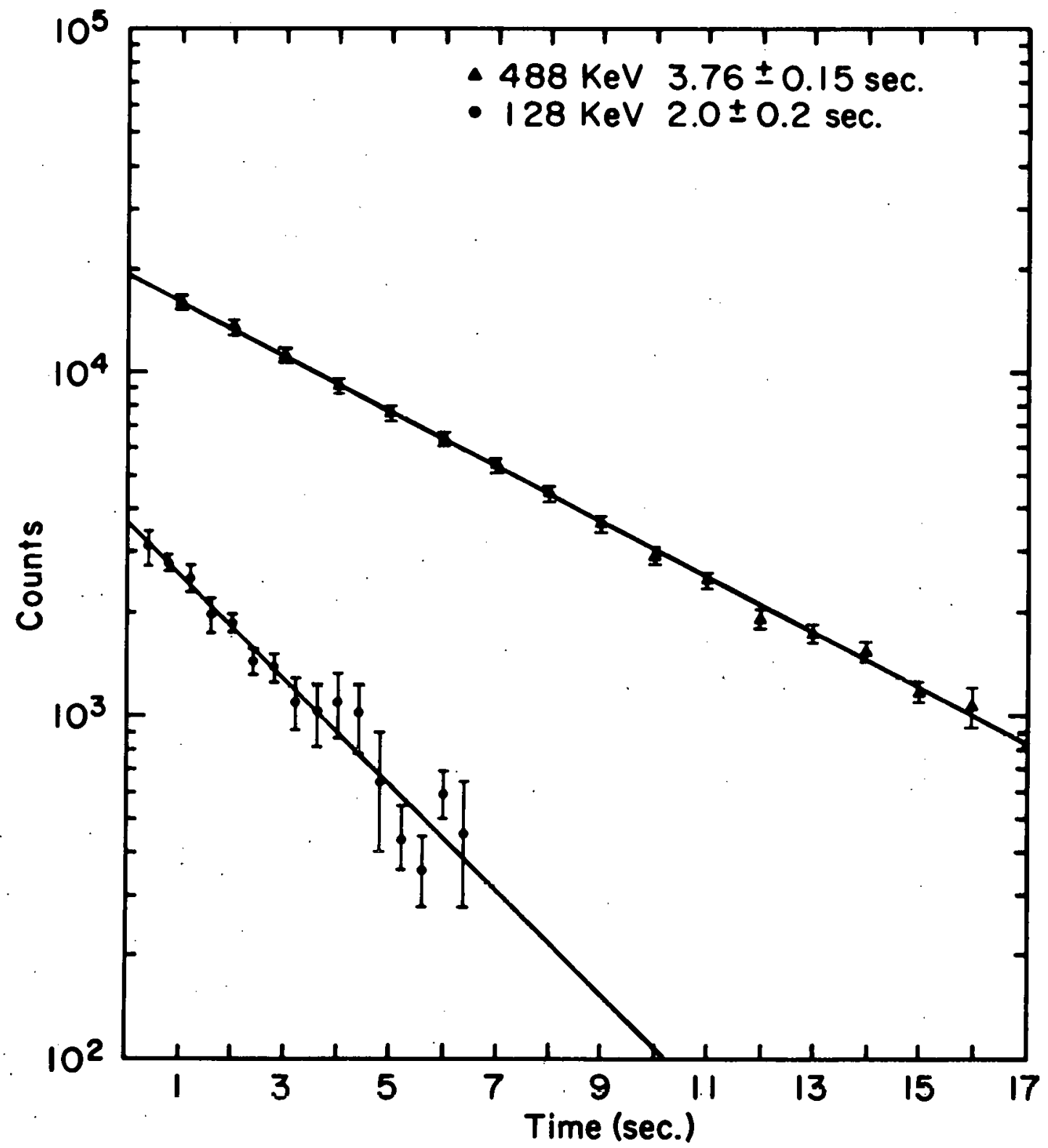

Fig. 9: Decay curves for the decay of $118 \mathrm{Ag}$ 1somers. 


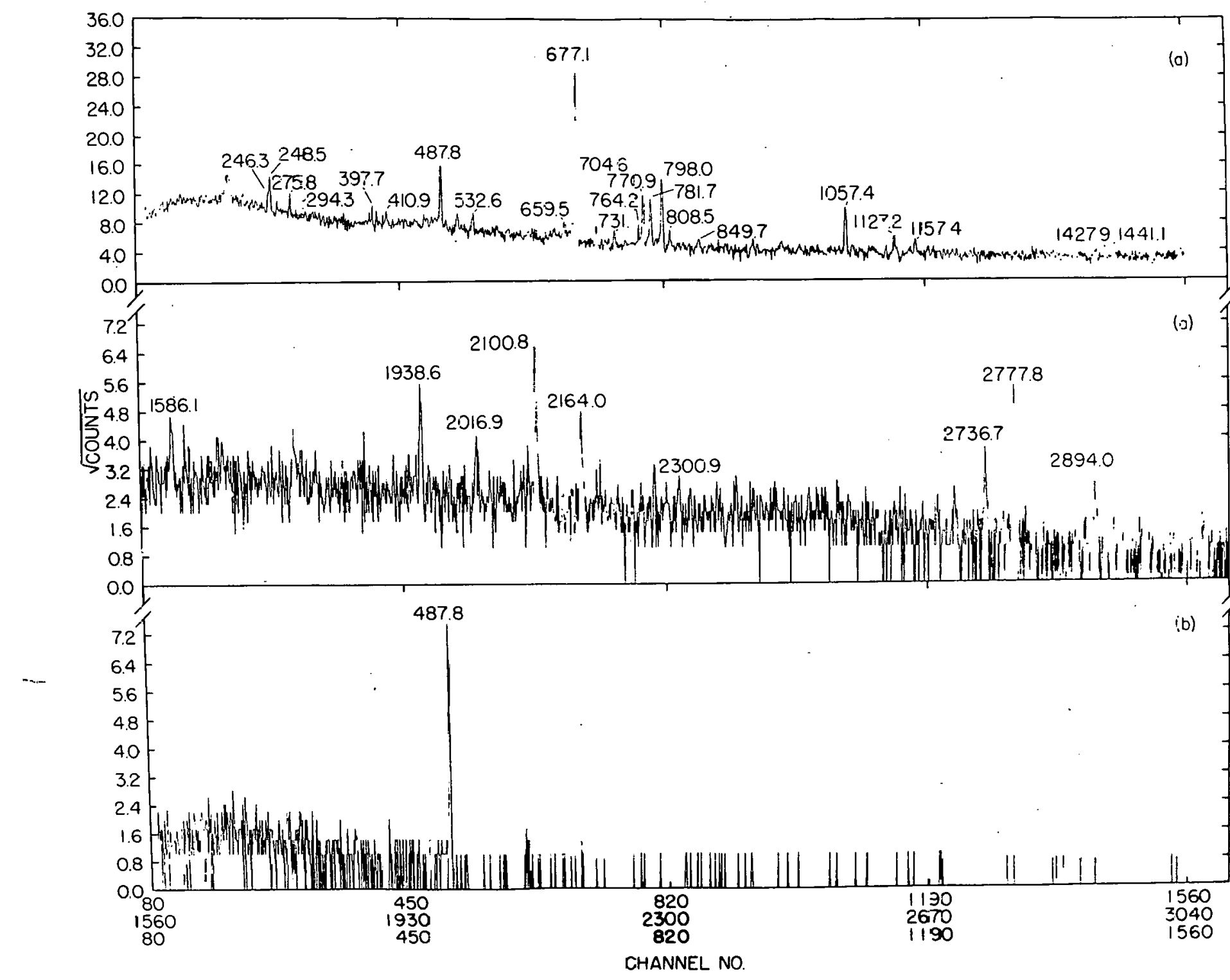

Fig. 10: Gamma spectra in coincidence with the (a) 48.3- and (b) 2778-keV $r$ rays from $118 \mathrm{Ag}$ decay. 


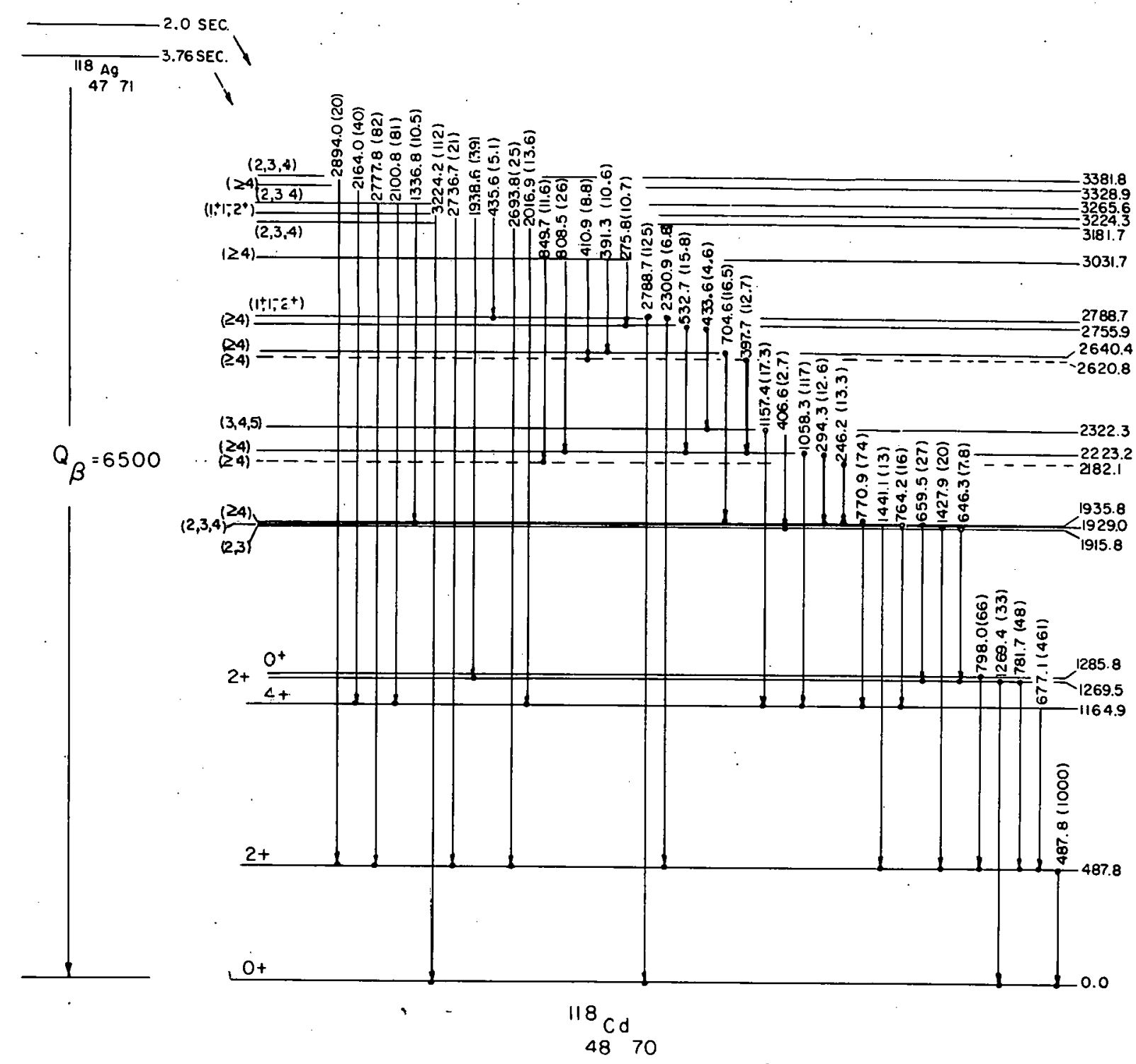

Fig. 11: Decay scheme for ${ }^{118} \mathrm{Ag}$. 
levels in ${ }^{118} \mathrm{Cd}$. It is clear though that levels like the one at $2788 \mathrm{keV}$ which decays directly to the ground state are fed primarily by the low-spin ground-state isomer of ${ }^{118} \mathrm{Ag}$ while levels 1 ike the one at $1936 \mathrm{keV}$ which decays only to the $4^{+}$level at $1165 \mathrm{keV}$ are fed primarily by the high-spin excited-state isomer of ${ }^{118} \mathrm{Ag}$. Interpretation of the ${ }^{118} \mathrm{Cd}$ level scheme in terms of a rotation-vibration collective model is given by williams ${ }^{11}$. The preliminary results from this work are compared with those from the OSIRIS experiment $^{13}$ in Fig. 12 .

3.2 Decay of ${ }^{122} \mathrm{Ag}$ to Levels in ${ }^{1.22} \mathrm{Cd}$

${ }^{122} \mathrm{Cd}$ is the most neutron-rich nucleus of $\mathrm{Cd}$ about which leverel information exists. ${ }^{122} \mathrm{Ag}$ was first reported by Fogelberg et al. ${ }^{13}$ on the basis of measurements made at the OSIRIS separator at Studsvik. The ${ }^{122} \mathrm{Ag} \mathrm{T}_{1 / 2}$ was measured to be $1.5 \pm 0.5 \mathrm{sec}$. and only two $\gamma$ rays at 570 and $760 \mathrm{keV}$ were observed. 'l'heir intensities were not given. The decay study of ${ }^{122} \mathrm{Ag}$ was the first one to be cumpleted with the TRISTAN II facility and the resules are discussed below.

A $Y$ singles run was made in which activity was collected on the tape of our MTC system. 'l'he tape was moved every 3 sec. to minimisc activity from the ${ }^{122} \mathrm{Cd}$ and ${ }^{122}$ In daughters. The run time was 12 hours and both Ge(TL) alld LEPS detectors were used. The spectrum trom $/ U$ to $1450 \mathrm{keV}$ is sliuwn $1 \mathrm{ll}$ Fig. 13. Six $\gamma$ rays were observed from ${ }^{122} \mathrm{Ag}$ decay. It is interesting to note that the intensity of the ${ }^{122} \mathrm{Ag} \gamma$ rays is weak compared to those from ${ }^{11.8 \mathrm{Ag}}$. This is due to a combination of the shorter ${ }^{\prime} \mathrm{l} 1 / 2$ and lower fission yield of ${ }^{122} \mathrm{Ag}$.

The $\mathrm{T}_{1 / 2}$ was determined as for ${ }^{118} \mathrm{Ag}$ by $\gamma$ multispectral scaling. The decay curve for the $569-\mathrm{keV} \gamma$ ray is shown in Fig. 14. The value obtained 
(a)

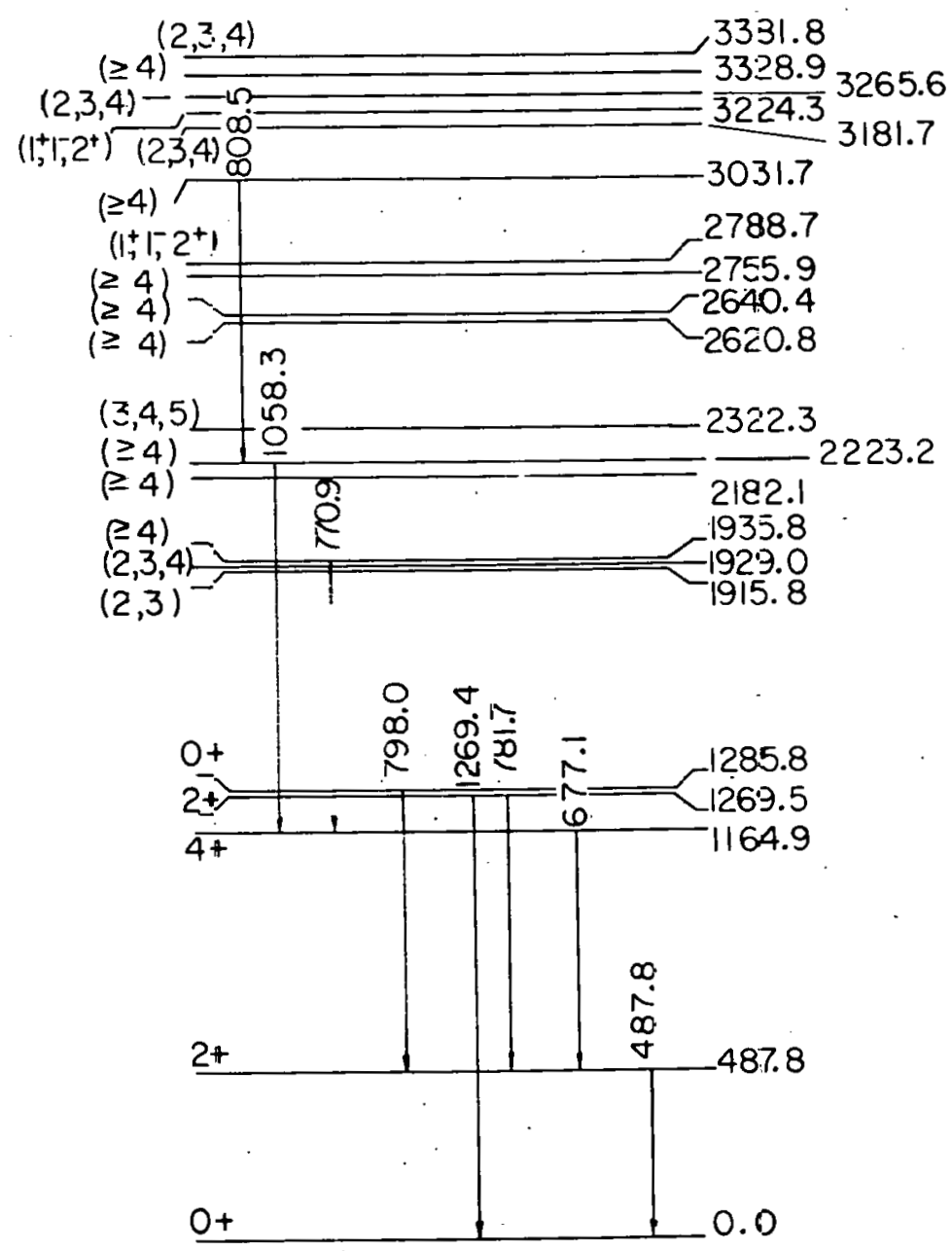

(b)

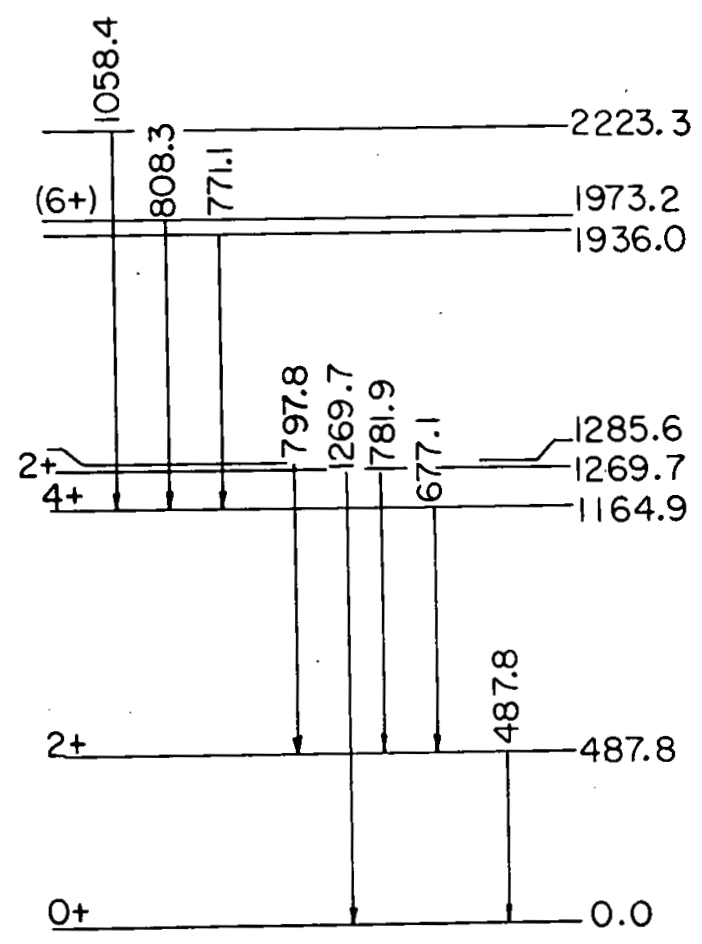

Fig. 12: Comparison of the results from this work with those from Ref. 13. 


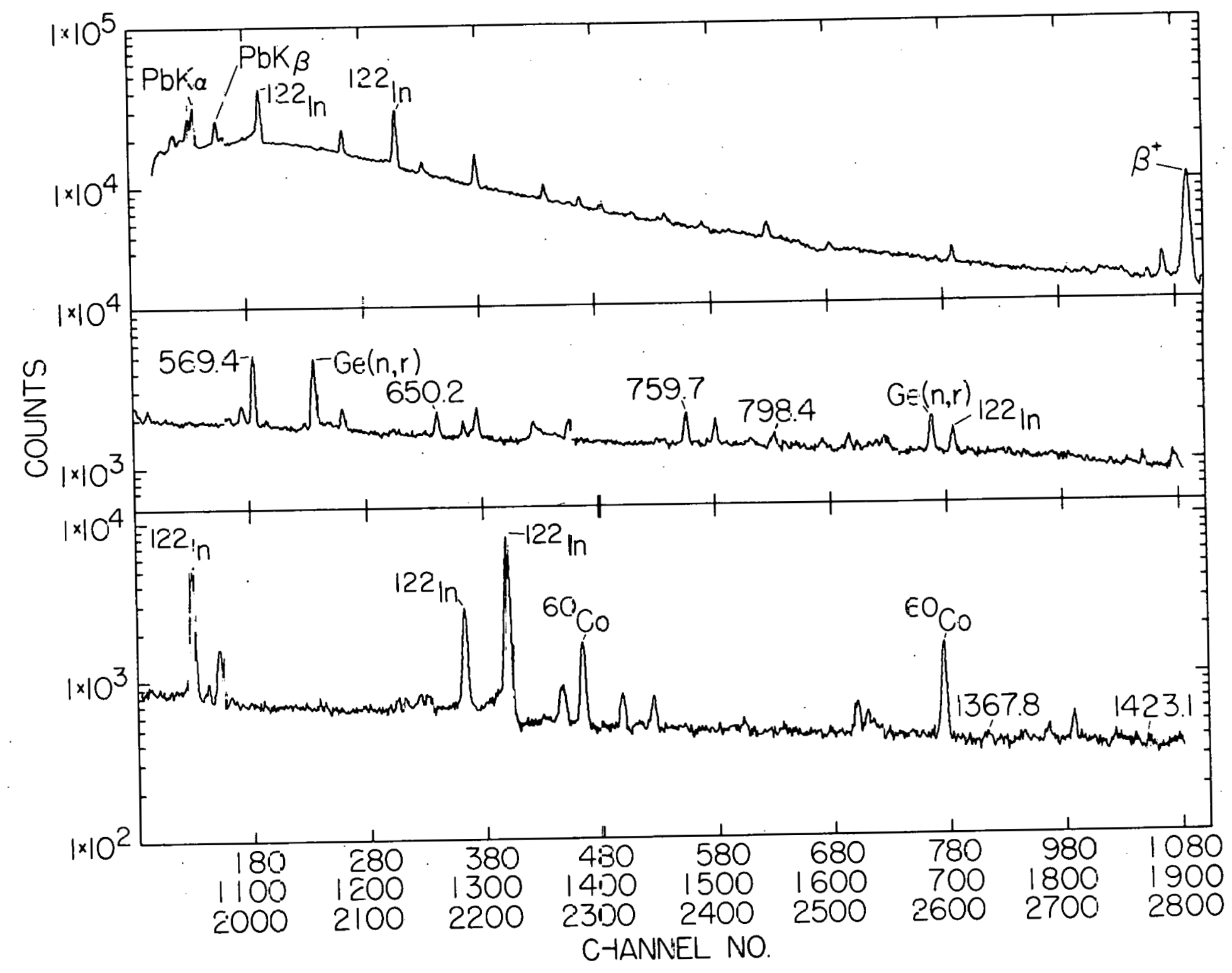

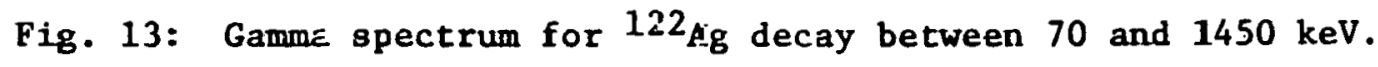




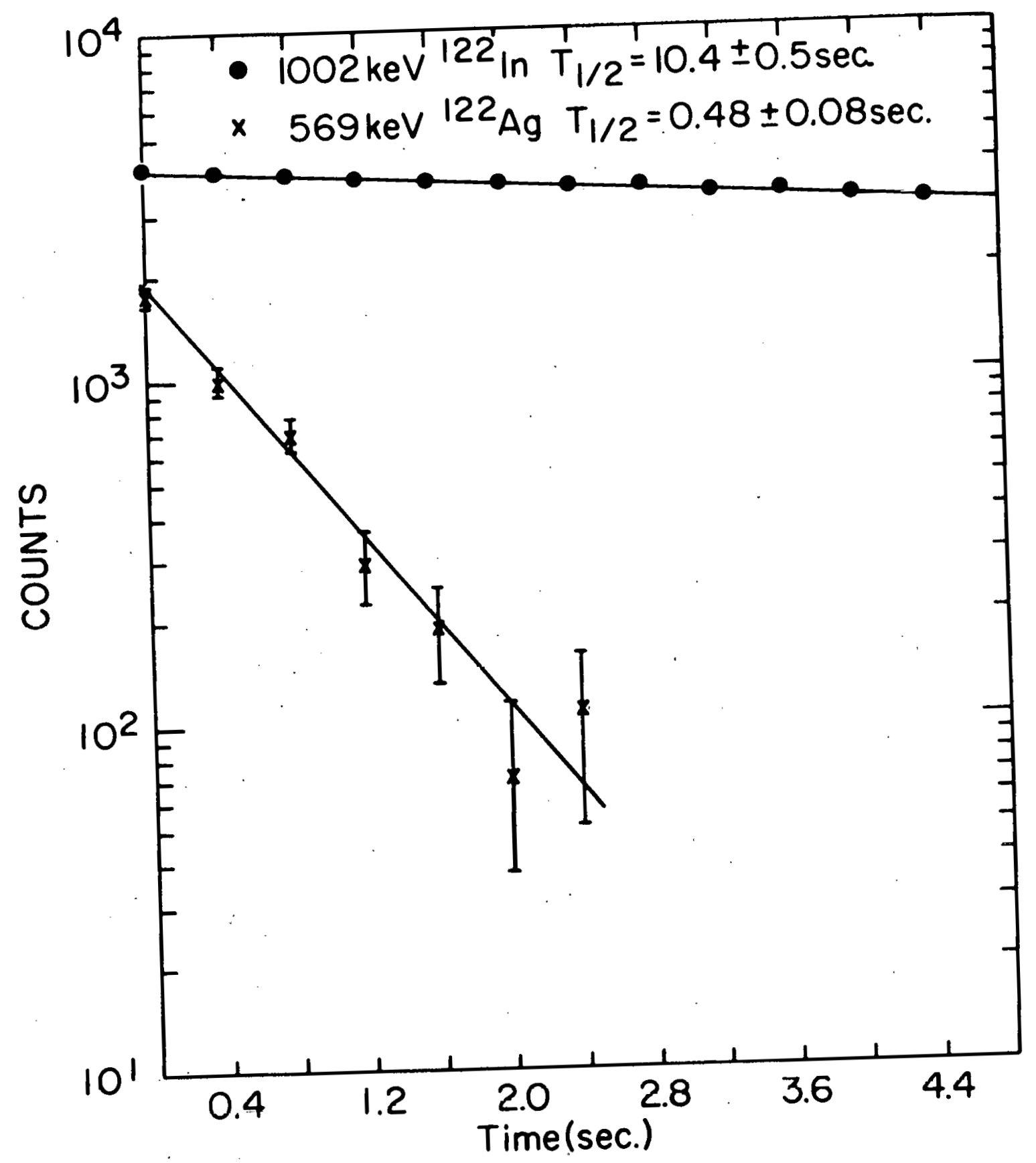

Fig. 14: Decay curve for the decay of ${ }^{122} \mathrm{Ag}$. 
for the ${ }^{122} \mathrm{Ag} \mathrm{T} \mathrm{T}_{1 / 2}$ was $0.48 \pm 0.08 \mathrm{sec}$. which is much smaller than the value $^{13}$ of $1.5 \pm 0.5 \mathrm{sec}$. obtained at OSIRIS. A $\gamma \gamma$-coincidence measurement was also made. Definite coincidences were observed in four $\gamma$ ray gates. Representative coincidence spectra in coincidence with the 569and $760-\mathrm{keV} \gamma$ rays are shown in Fig. 15.

The above results were used to construct a decay scheme for ${ }^{122} \mathrm{Ag}$ which is shown in Fig. 16. The first excited state at $569 \mathrm{keV}$ is probably $2^{+}$as is the case fur all even-even Cd nuclei. The level at 1368 $\mathrm{keV}$ is also $2^{+}$since $i t$ decays to both the ground and tirst excitcd states. The $1329-\mathrm{keV}$ level was assigned a $\mathrm{J}^{\pi}$ of $4^{+}$due to the strength of the $760-\mathrm{keV}$ transition and the fact that the $4^{+}$is lower in energy than the $2^{+}$member of the vibrational triplet for ${ }^{118} \mathrm{Ag}$ and ${ }^{120} \mathrm{Ag}$. The $\log \mathrm{ft}$ 's of 5.3 and 5.8 for $\beta$ feedings to the $569-$ and $1329-\mathrm{keV}$ levels respectively limit the $\mathrm{J}^{\pi}$ for the ${ }^{122} \mathrm{Ag}$ ground state to $3^{+}$. A survey of the available shell model orbitals indicates that the configuration for the ${ }^{122} \mathrm{Ag}$ ground state is probably $\pi\left(g_{9 / 2}\right) \cup\left(\mathrm{d}_{3 / 2}\right)$. We favor a $J^{\pi}$ of $3^{\prime}$ or $4^{+}$for the $1979-\mathrm{keV}$ level on the basis of its $\log \mathrm{ft}$ of 5.3 and the absence of a $\gamma$ transition to either of the $2^{+}$states.

Measurements on the decay of ${ }^{120} \mathrm{Ag}\left(\mathrm{T}_{1 / 2}=1.2 \mathrm{sec}.\right)$ and ${ }^{120} \mathrm{Ag}^{*}\left(\mathrm{~T}_{1 / 2}=\right.$ $0.3 \mathrm{sec}$. ) to levels in ${ }^{1.20} \mathrm{Cd}$ have been completed at TRISTAN II and analysis of the data is in progress. Of a total of $65 \gamma$ rays observed, 37 have been placed in a preliminary level scheme consisting of levels up to $3559 \mathrm{keV}$. The details of this study will not be presented here, but our results for low-lying levels in ${ }^{120} \mathrm{Cd}$ will be used in the discussion of the systematics of even-even neutron-rich Cd nuclei that follows. 


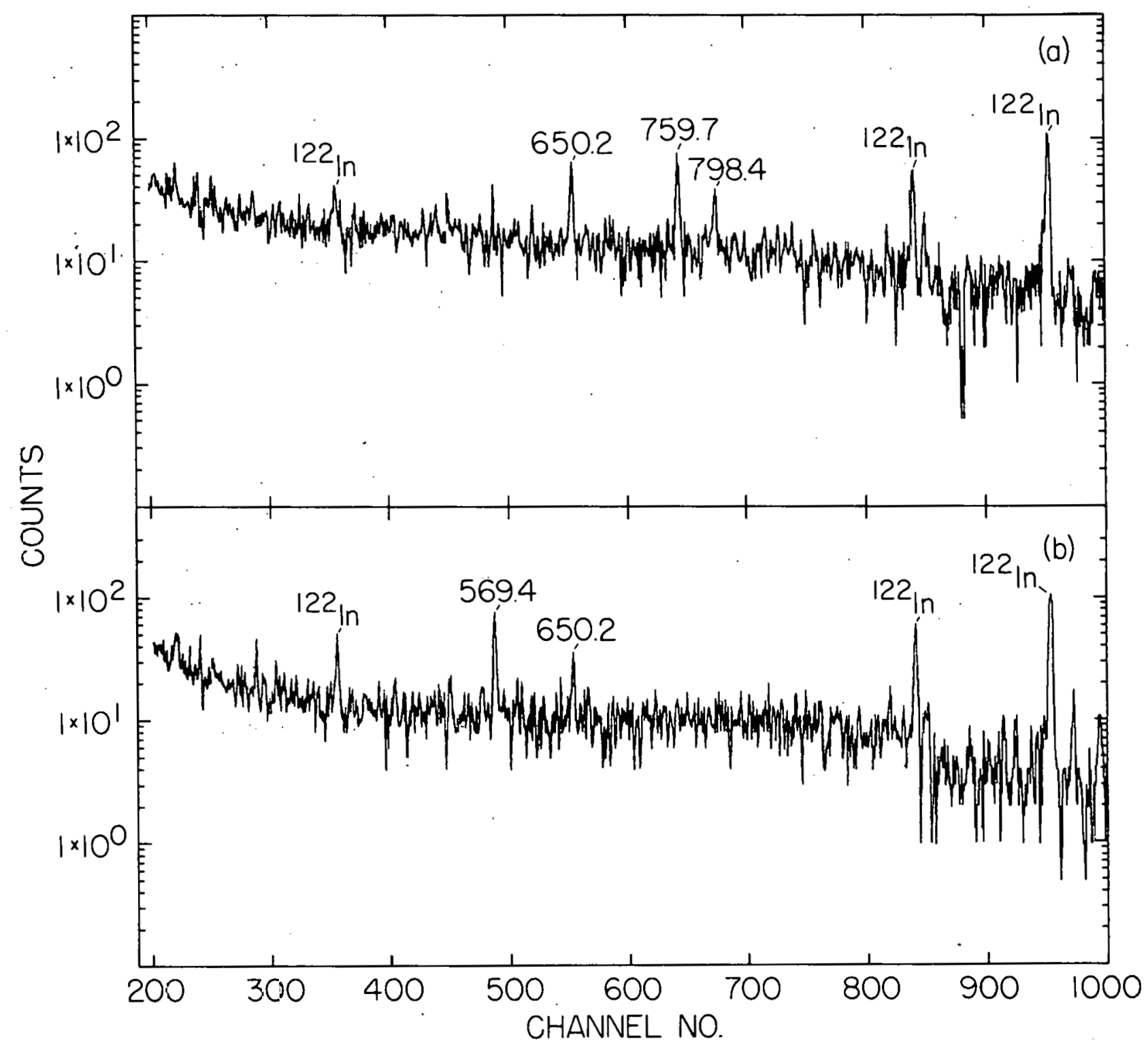

Fig. 15: Gamma spectra in coincidence with the (a) 569- and (b) 760-keV $\gamma$ rays from ${ }^{122} \mathrm{Ag}$ decay. 


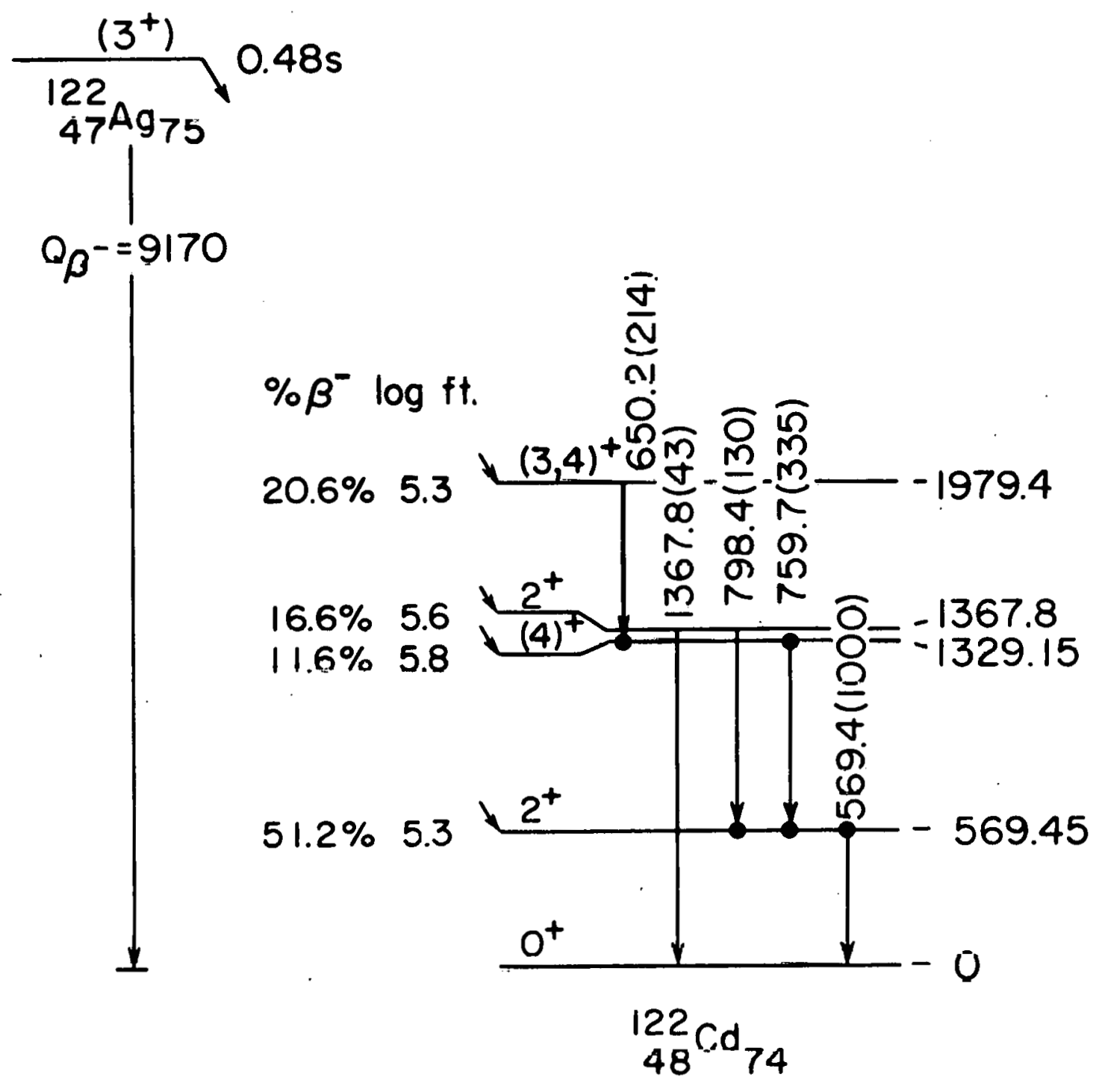

F1g. 16: Decay scheme for ${ }^{122} \mathrm{Ag}$. 


\subsection{Systematics for Even-Even Cd Nuclei}

The systematics for the low-lying levels in even-even $C d$ nuclei are given in Fig. 17. The level energies for ${ }^{118} \mathrm{Cd},{ }^{120} \mathrm{Cd}$, and ${ }^{122} \mathrm{Cd}$ are those measured at TRISTAN II. Several features are of interest. The first excited $2^{+}$state (one phonon quadrupole state in the vibrational model) is fairly constant in energy but reaches a minimum at $\mathrm{A}=118$. The rise in energy is quite symmetric on each side of $A=118$. One might expect the $2^{+}$state to have its lowest energy at $A=114$ midway between the $N=50$ and $N=82$ closed shells where the nucleus might be expected to be the softest. The first exctited $4^{+}$state (member of the two phonon vibrational triplet) is typically a little more than twice the energy of the one phonon $2^{+}$state. The behavior of the $4^{+}$state with neutron number is remarkably similiar to that of the one phonon state with a energy minimum at $A=118$. The behavior of the second excited $2^{+}$state $\left(2^{+}\right.$memher of the two phonon vibrational triplct) is quite different. Its energy is about twice that of the one phonon state but its energy minimum is at $\mathrm{A}=114$ (mid-shel1). In the rotational-vibrational mode1 of Williams ${ }^{11}$ the energy of this state is largely determined by the asymmetry parameter. The minimum at mid-shell is consistent with maximal collective motion near mid-shell.

Our preliminary results on levels in ${ }^{118} \mathrm{Cd}$ are in good agreement with the rotational-vibrational model ${ }^{11}$ but this model is unable to account correctly for the energy and $\gamma$ branching of the level in ${ }^{122} \mathrm{Cd}$ (see Fig. 16) at $1979 \mathrm{keV}$. 'This breakdown in the rotational-vibrational model may be due to the neglect of the single-particle character of the ${ }^{122} \mathrm{Cd}$ nucleus, This is not surprising since $C \cdot d(z=48) 16$ only two 

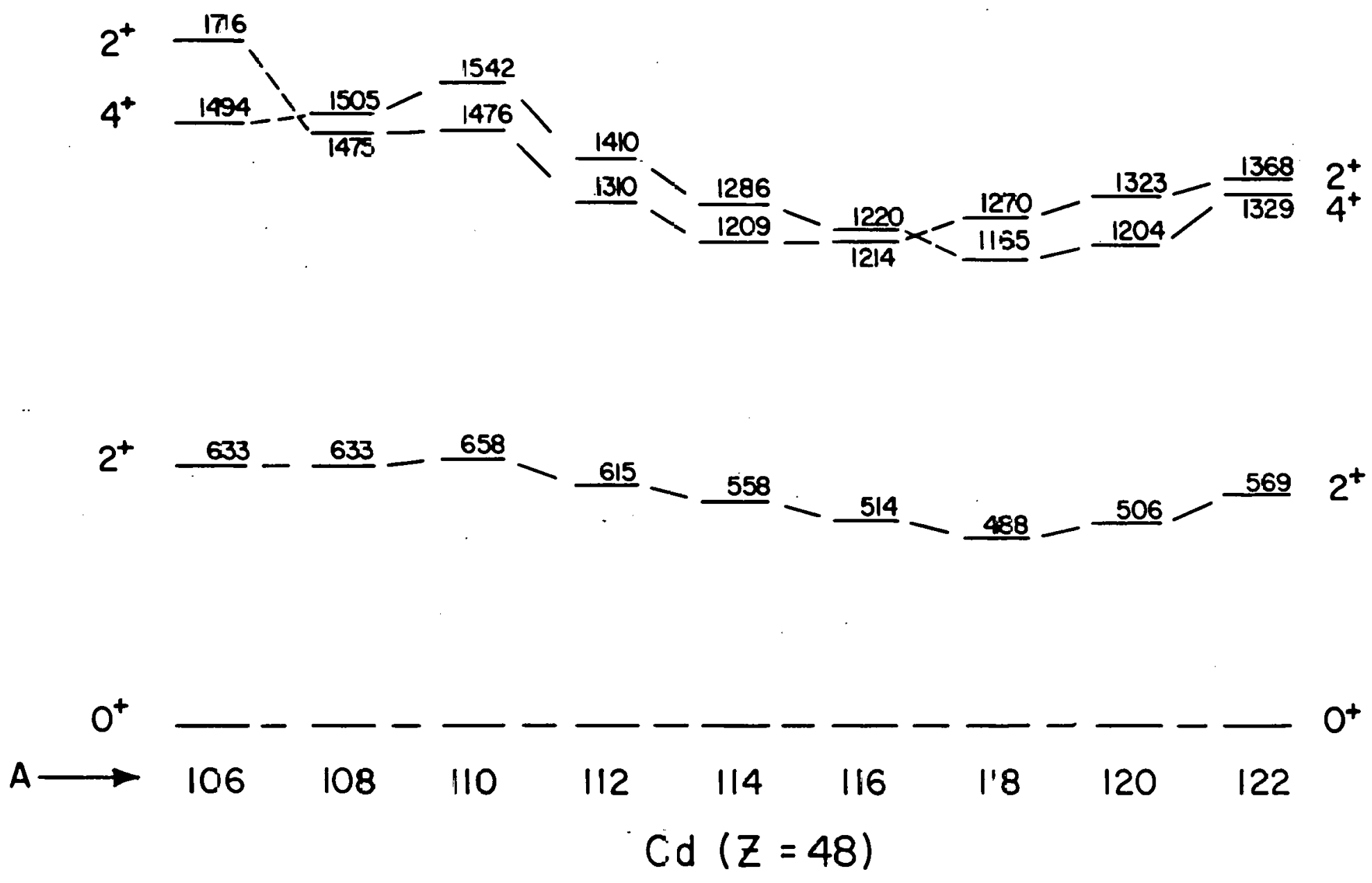

Fig. 17: Systematics of low-lying levels in even-even Cd nuclei. 
protons away from the $Z=50$ closed shell. Also as we add neutron pairs we are approaching the $\mathrm{N}=82$ closed shell.

\section{Studies in the Tin Region at TRISTAN II}

The $\operatorname{Sn}(Z=50)$ nuclei have been subjected to intensive study for many years due to the fact that they contain a magic number of protons. In spite of this, our knowledge of the structure of the neutron-rich Sn nuclei with $\mathrm{A}=126$ and above is very incomplete. Almost all of the knowledge that does exist comes from work done at the OSIRIS separator. ${ }^{14}$ The structure of $\mathrm{Sn}$ nuclei between $\mathrm{A}=126$ and 132 is also of great interest in determining to what degree the magic numbers $Z=50$ and $N=82$ are still magic far to the neutron-rich side of stability $\left({ }^{132} \mathrm{Sn}\right.$ region). We report below on decay studies ${ }^{15-17}$ of ${ }^{126} \mathrm{Cd},{ }^{126} \mathrm{In}$, and 128 In:

4.1. Structure of ${ }^{126} \mathrm{Sn}$ and ${ }^{128} \mathrm{Sn}$ from the Dccay of In Fission Froducls

One of the principal objectives of the TRISTAN II program was to extend the systematics of even-even $\mathrm{Sn}$ nuclides toward doubly-magic neutron-rich ${ }^{132} \mathrm{Sn}$. We therefore undertook a detailed decay study of ${ }^{126}$ In and ${ }^{128}$ In. Some information on the decay of ${ }^{126}$ In and ${ }^{128}$ In has been obtained at the OSIRIS separator. 14

In the study of ${ }^{126}$ In decay, a $T_{1 / 2}$ of $1.6 \pm 0.2 \mathrm{sec}$ was obtained by $\gamma$ multispectral scaling. Of $42 \gamma$ rays assoctated with the decay of ${ }^{126}$ In, 35 were placed in a preliminary ${ }^{126} \mathrm{Sn}$ level scheme which is shown in F1g. 18. Levels also seen at OSIRIS are indicated by an asterisk. In the study of the $A=128$ decay chain several different $T_{1 / 2}$ 's were observed. Their relationship is not completely cilear but an activity with a halfIffe of $7.1 \mathrm{sec}$. is associated with the decay of the $7^{-}$isomeric state in 


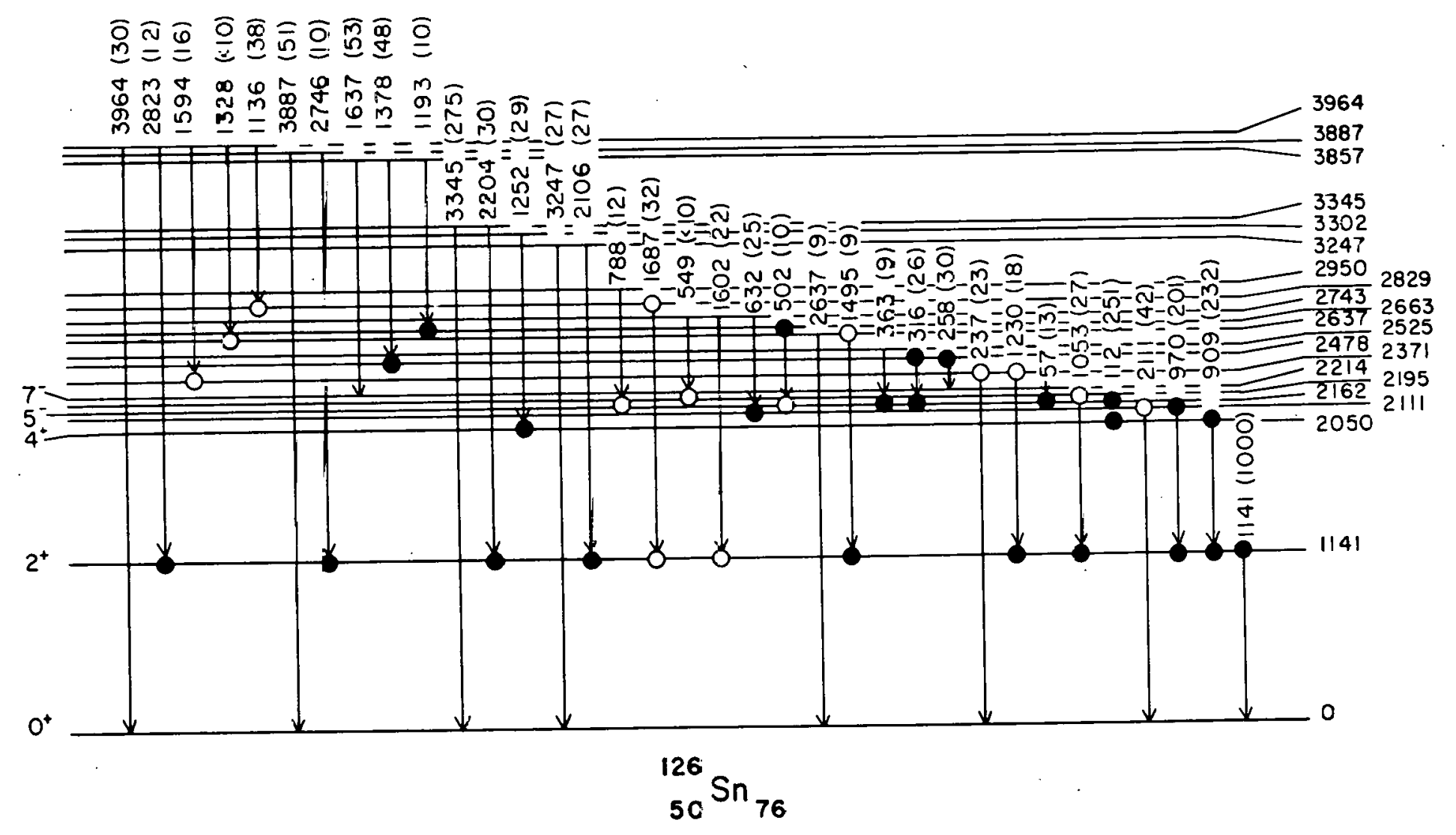

Fig. 18: Level scheme for ${ }^{126} \mathrm{Sn}$. 
${ }^{128} \mathrm{Sn}$ at $2091 \mathrm{keV}$ and an activity with a half-1ife of $0.83 \mathrm{sec}$. is associated with ${ }^{128}$ In decay. A total of $50 \gamma$ rays have been placed in a preliminary ${ }^{128}$ Sn level scheme which is shown in Fig. 19. In the work at OSIRIS only the excited states at $1169,2001,2092$, and $2121 \mathrm{keV}$ were observed. Systematics for even-even neutron-rich $\mathrm{Sn}$ nuclides are given in Fig. 20. Although our results are more detalled than those from Ref. 14 our analysis is not complete and $J^{\pi}$ 's have not been assigned for the new levels. Several systematic features of the levels are worthy of note. First the first-excited $2^{+}$level rises slowly as $\mathrm{N}=82$ is approached. This is consistent with the idea that the nucleus becomes more tightly bound as the neutron number nears 82 . In contrast to this the $4^{+}, 5^{-}$, and $7^{-}$levels decrease in energy as $\mathrm{N}=82$ is approached. This feature is not well understood, but a simfliar effect ${ }^{5}$ has been noted for low-1ying levels in the even-even $\mathrm{N}=82$ nuclides.

\subsection{The Decay of ${ }^{126} \mathrm{Cd}$}

We report here the first decay scheme for ${ }^{126} \mathrm{Cd}$. This very neutronrich nucleus has been observed ${ }^{2}$ at the OSIRIS separator but no decay scheme was given. In a survey of $A=126$ activity at TRISTAN II, several $\gamma$ rays belonging to ${ }^{126} \mathrm{Cd}$ were observed. A $\gamma$ multispectral scaling measurement was made and the $\mathrm{T}_{1 / 2}$ of $0.51 \pm 0.01 \mathrm{sec}$. for ${ }^{126} \mathrm{Cd}$. was obtained from the 260 - and $428-\mathrm{keV} \gamma$ rays. The ${ }^{126} \mathrm{Cd}$ decay curve is given in Fig. 21.

Singles spectra at $A=126$ were taken in which the tape of the MTC was moved every $2 \mathrm{sec}$. in order to minimize activitles from longer lived ${ }^{126}$ In. The resulting spectrum was shown in Fig. 4. A total of $9 \gamma$ rays were placed in a preliminary ${ }^{126} \mathrm{Cd}$ decay scheme which is shown in Fig. 22. 


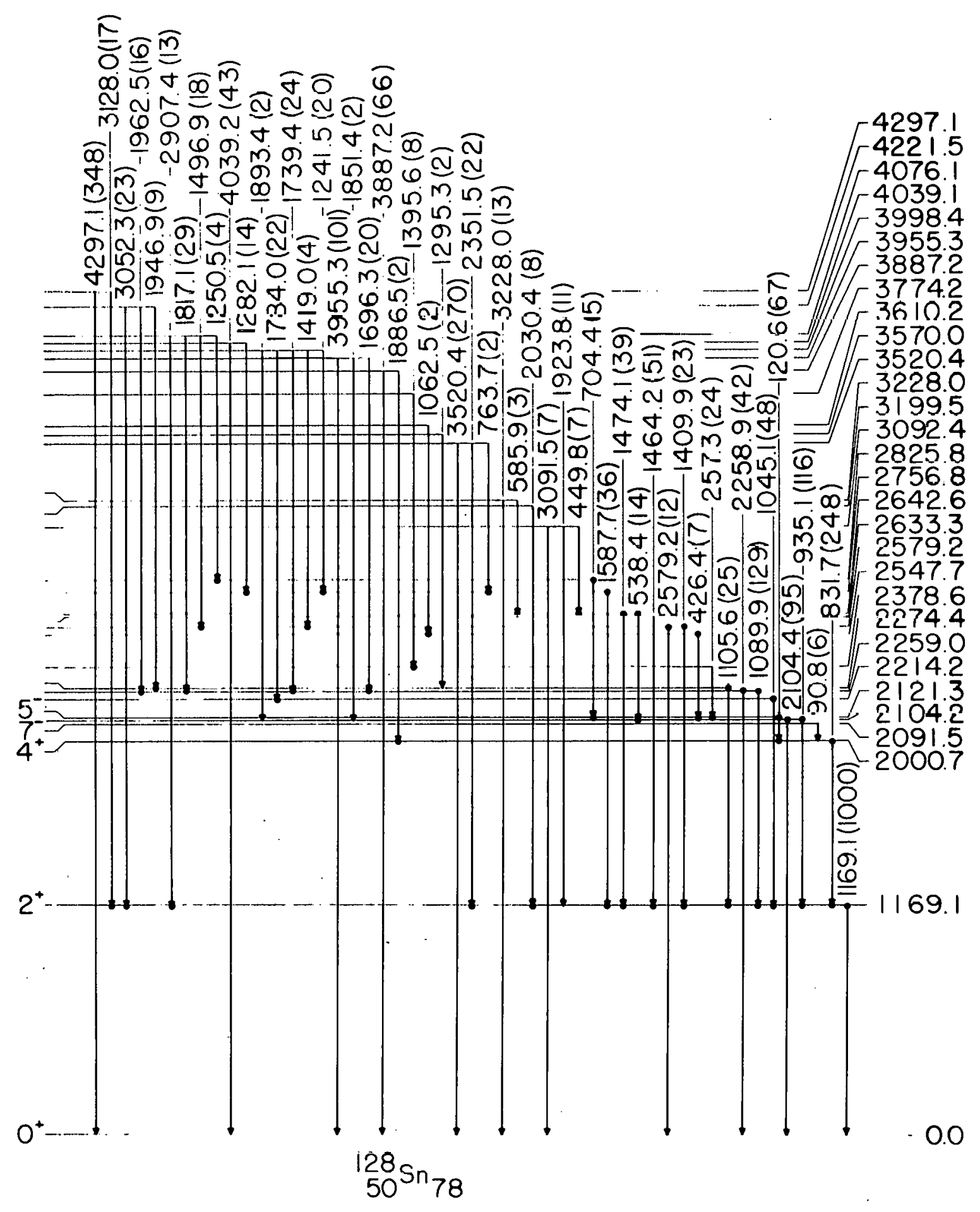

Fig. 19: Level scheme for ${ }^{128} \mathrm{Sn}$. 

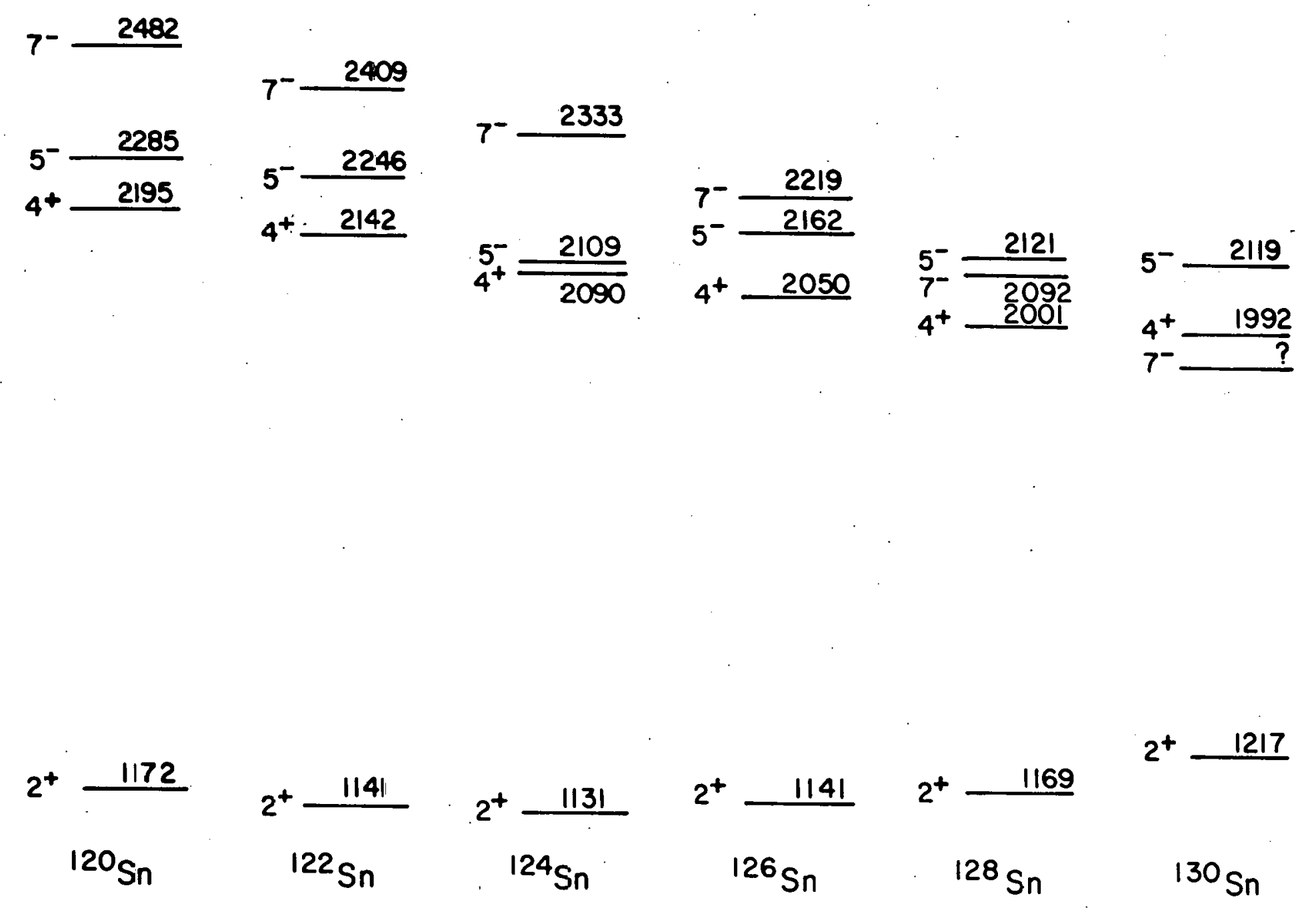

Fig. 20: Systematics for neutron-rich even-even Sn nuclel. Levels from Ref. 14 except for $A=126$ and 128 where our results are given. 


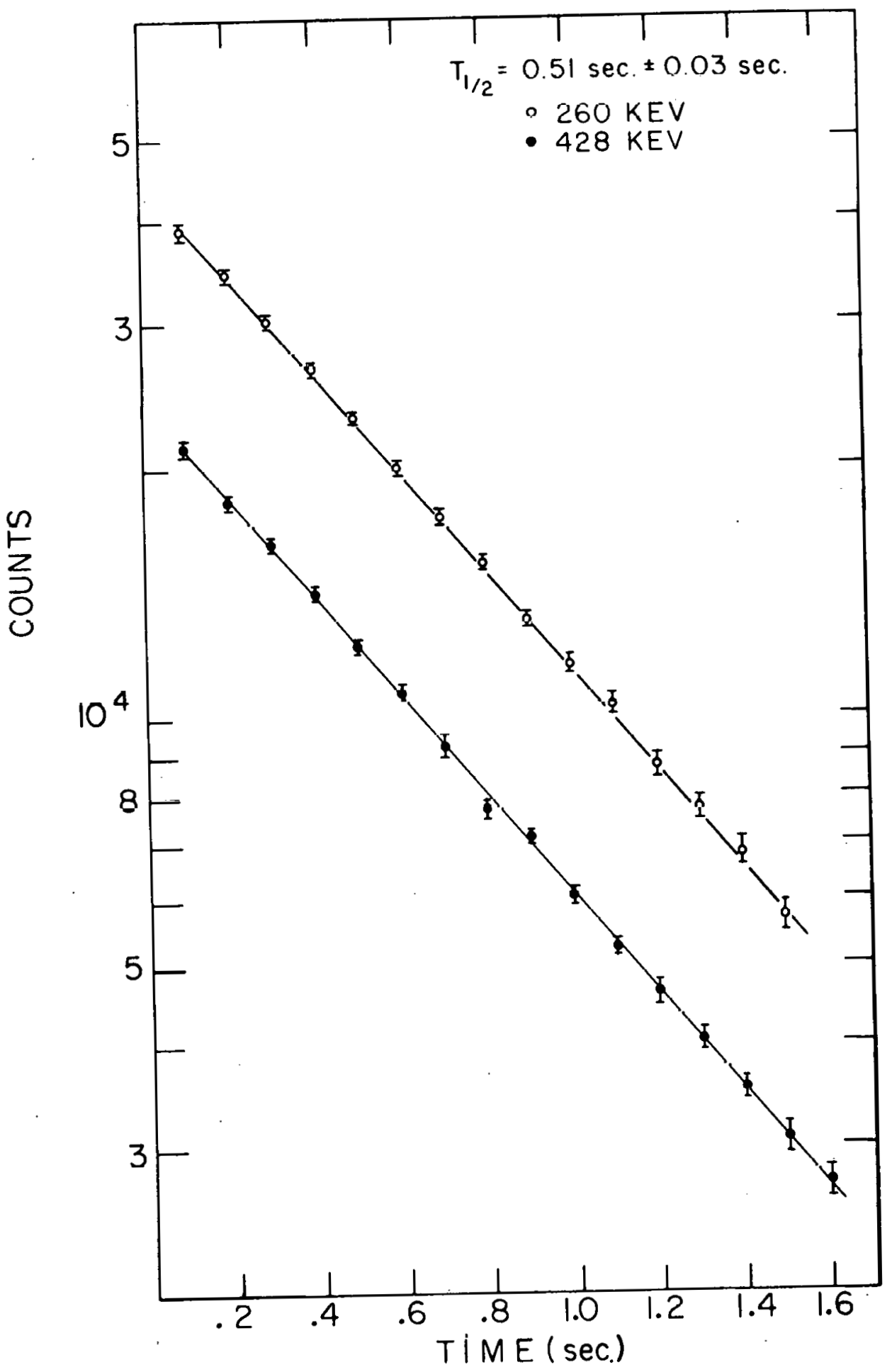

F1g. 21: Decay curve for the decay of $126 \mathrm{Cd}$. 


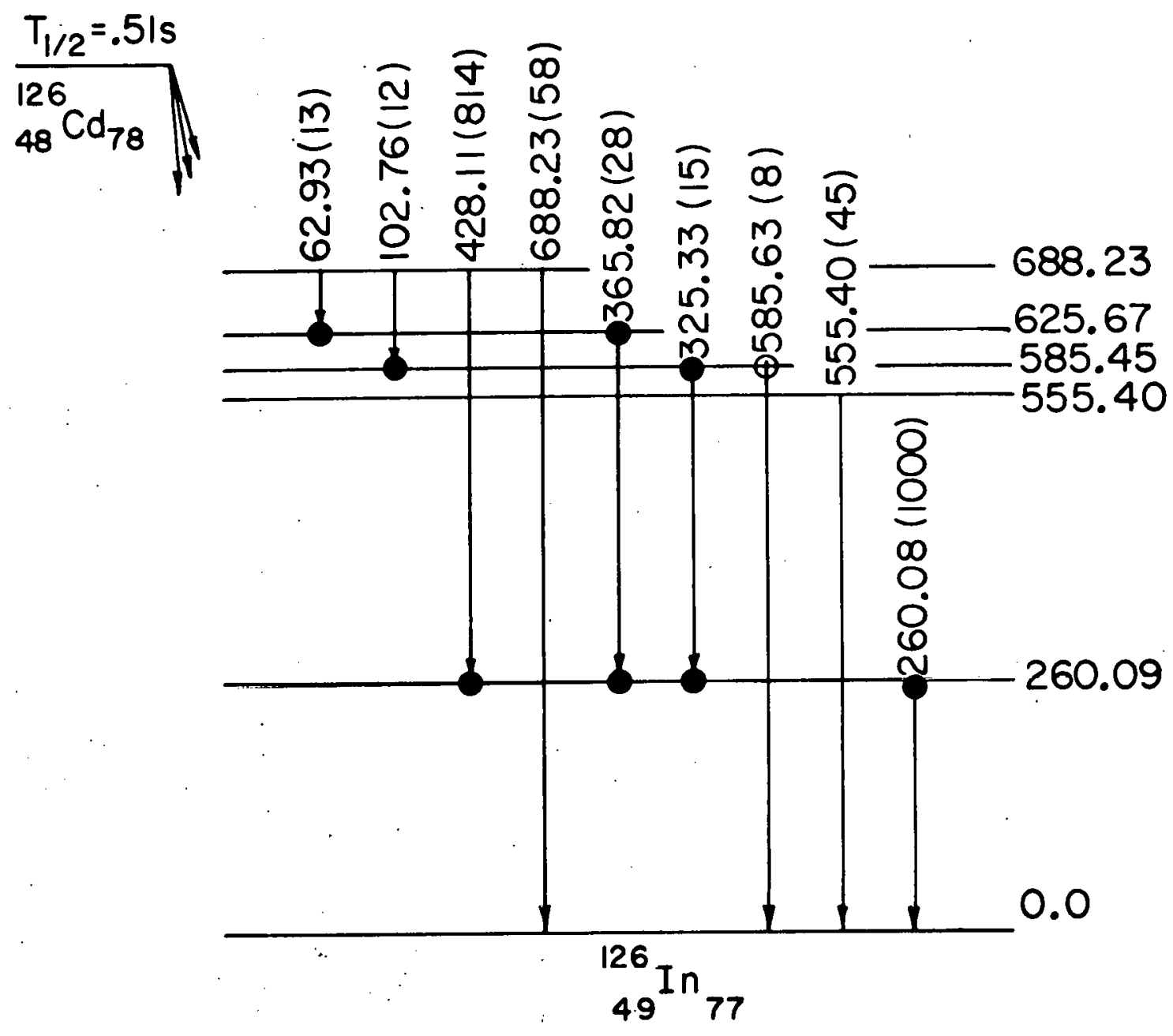

Fig. 22: Decay scheme for ${ }^{126} \mathrm{Cd}$. 
No discussion of odd-odd In systematics is possible since practically no information on levels in other In nuclei in this region is available. Such nuclei are interesting since thetr low-lying levels should be describable in terms of one proton hole in the $z=50$ closed shell coupling with an odd neutron between $\mathrm{N}=50$ and $\mathrm{N}=82$.

\section{Possibilities for Future Studies at TRISTAN II}

During the first year of operation spectroscopic studies at TRISTAN II have concentrated on even $A$ nuclei in the region just below singly-magic Sn. There are several other regions of great interest which can be studied with our present system. A discussion of future possiblities follows.

5.1. The Region Near Doub1y-Magic ${ }^{78} \mathrm{Ni}$

It is of interest to determine if the magic numbers near stability remain magic far from stability. The doubly-magic nucleus ${ }^{78} \mathrm{Ni}$ is probably too far from stability to enable a study of 1ts properties using a fission source. Nevertheless the region just above it in the nuclide chart is accessible to study at TRISTAN II. This is possible due to the good yields and short holdup times fur $\mathrm{Zn}$ and $\mathrm{Ga}$ in our ion source as can be seen from the $4 \pi$ fission product yield curve in Fig. 1 and the $A=78 \gamma$ spectrum in Fig. 2. In particular it should be possible to study a number of $\mathrm{N}=50$ nuclei just above ${ }^{78} \mathrm{Ni}$.

The nuclide chart for $N=50$ just above doubly-magic ${ }^{78} \mathrm{Ni}$ is shown in Fig. 23. It should be possible to determine the structure of the $\mathrm{N}=50$ nuclei starting from ${ }^{81} \mathrm{Ga}\left({ }^{78} \mathrm{Ni}\right.$ core +3 protons $)$ up to ${ }^{85} \mathrm{Br}\left({ }^{78} \mathrm{Ni}\right.$ core +7 protons). Wohn ${ }^{3}$ has shown that yields of ${ }^{82} \mathrm{Ga},{ }^{83} \mathrm{Ge},{ }^{84}$ As and ${ }^{85}$ Se should be large enough for decay studies. The yield of ${ }^{81} \mathrm{Zn}$ is 


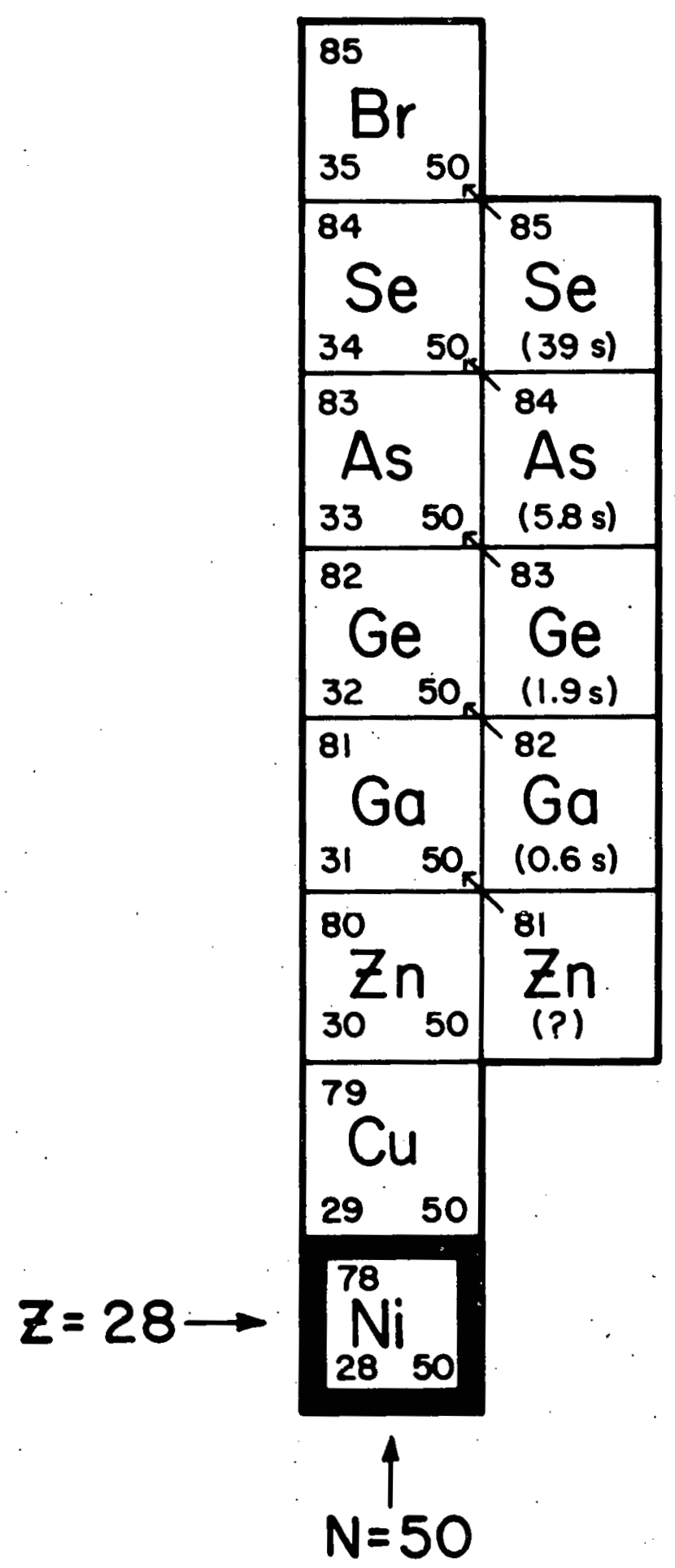

Fig. 23: The $N=50$ 11ne on the nuclide chart above doubly-mag1c $78_{\mathrm{N} 1}$. 
quite low but with increased neutron fluxes it should be sufficient for decay studies if its $\mathrm{T}_{1 / 2}$ is not too short. Identification of onequasiparticle states in ${ }^{81} \mathrm{Ga},{ }^{83} \mathrm{As}$, and ${ }^{85} \mathrm{Br}$. and location of the core breaking states in ${ }^{82} \mathrm{Ge}$ and ${ }^{84} \mathrm{Se}$ would be of great help in determining the degree to which ${ }^{78} \mathrm{Ni}$ is doubly-magic.

Preliminary studies of Ge nuclei in this region are in progress at TRISTAN II. Some data have been obtained ${ }^{18}$ on the decay of ${ }^{78} \mathrm{Ga}\left(\mathrm{T}_{1 / 2}=\right.$ 5 sec.). Systematics for low-Lying leveis in èven-even Ge nuclides is given in Fig. 24. The results shown for $A=78$ are from our work. These nuclei are unusual in that the $0^{+}$level lies very $10 \mathrm{w}$ and is the first excited state in ${ }^{72} \mathrm{Ge}$. One might expect that as the neutron number approaches the magtc number 50 the nucleus would become more tightly bound and the first excited $2^{+}$state would rise in energy. This is first noted in $\mathrm{Ge}$ in going from $\mathrm{A}=76$ to $\mathrm{A}=78$. Also one would expect the Ge nucleus to become more like a quadrupole vibrator as $\mathrm{N}=50$ is approached. Estimate of the yield ${ }^{3}$ for $\mathrm{Ga}$ isotopes indicates that it should be possible to study the structure of Ge nuclides out to singly magic ${ }^{82} \mathrm{Ge}$.

\subsection{The Doubly-Magic ${ }^{132} \mathrm{Sn}$ Region}

The region around neutron-rich ${ }^{132} \mathrm{Sn}$ is of great interest since it is the most accessible doubly-maglc reglon that is far from stability. Most of our knowledge of nuclei very close to ${ }^{132} \mathrm{Sn}$ has come from experiments carried out at the OSIRIS separator. A good set of references on that work is given by Rudstam. ${ }^{2}$ The status of our knowledge of nuclei consisting of $a^{132} \mathrm{Sn}$ core plus one or two particles or holes is given in Fig. 25. We have indicated the level structure of these nuclei as 


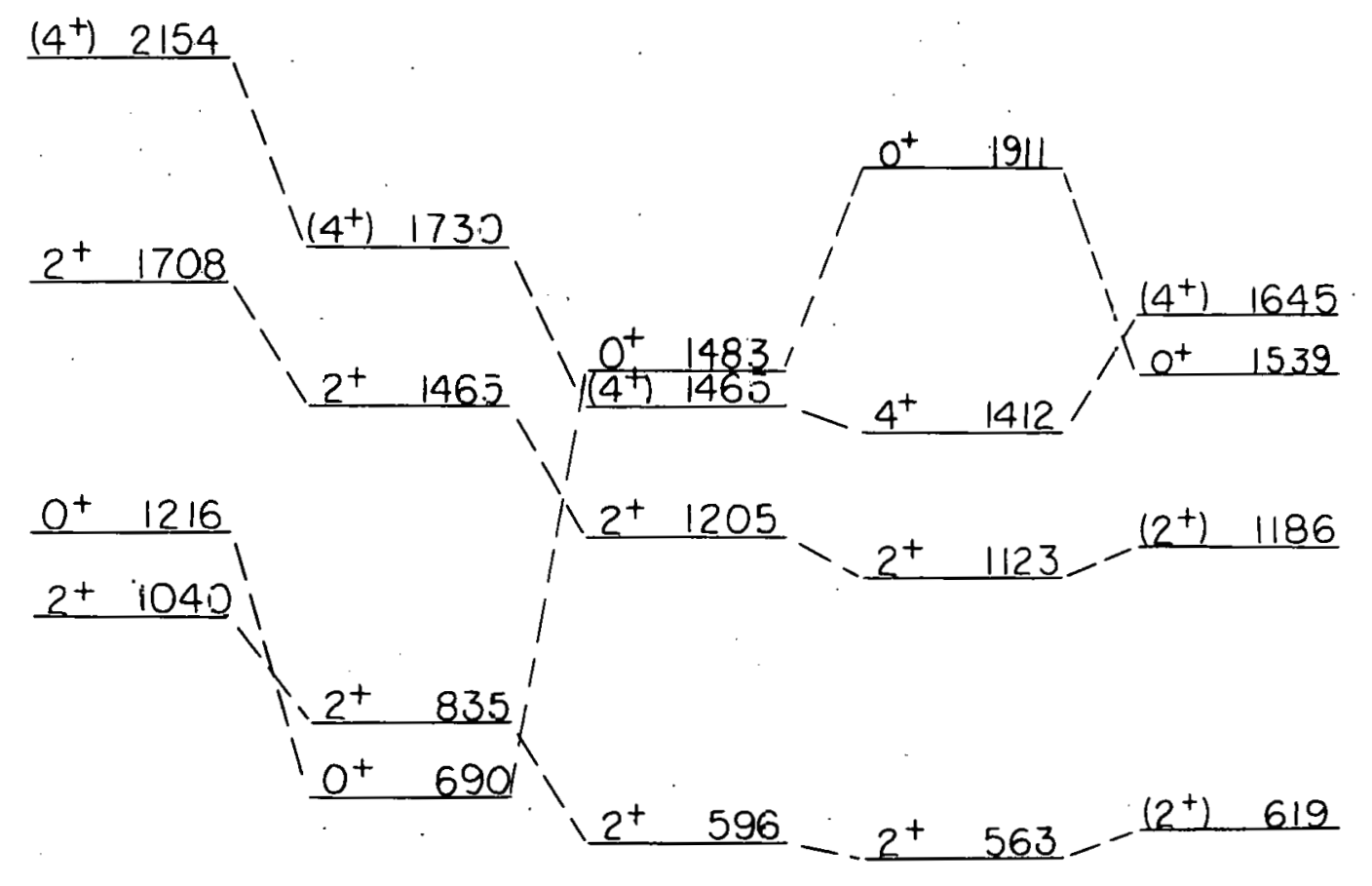

$$
\frac{\mathrm{O}^{+}}{{ }_{32}^{70} \mathrm{Ge}_{38}} \quad \frac{\mathrm{O}^{+}}{{ }_{32}^{72} \mathrm{Ge}_{40}} \quad \frac{\mathrm{O}^{+}}{{ }_{32}^{74} \mathrm{Ge}_{42}} \quad \frac{\mathrm{O}^{+}}{{ }_{32}^{76} \mathrm{Ge}_{44}} \quad \frac{\mathrm{O}^{+}}{{ }_{32} \mathrm{Ge}_{46}} \quad \frac{\mathrm{O}^{+}}{{ }_{32}^{80} \mathrm{Ge}_{48}} \quad \frac{\mathrm{O}_{88}^{+}}{{ }_{32} \mathrm{Ge}_{50}}
$$




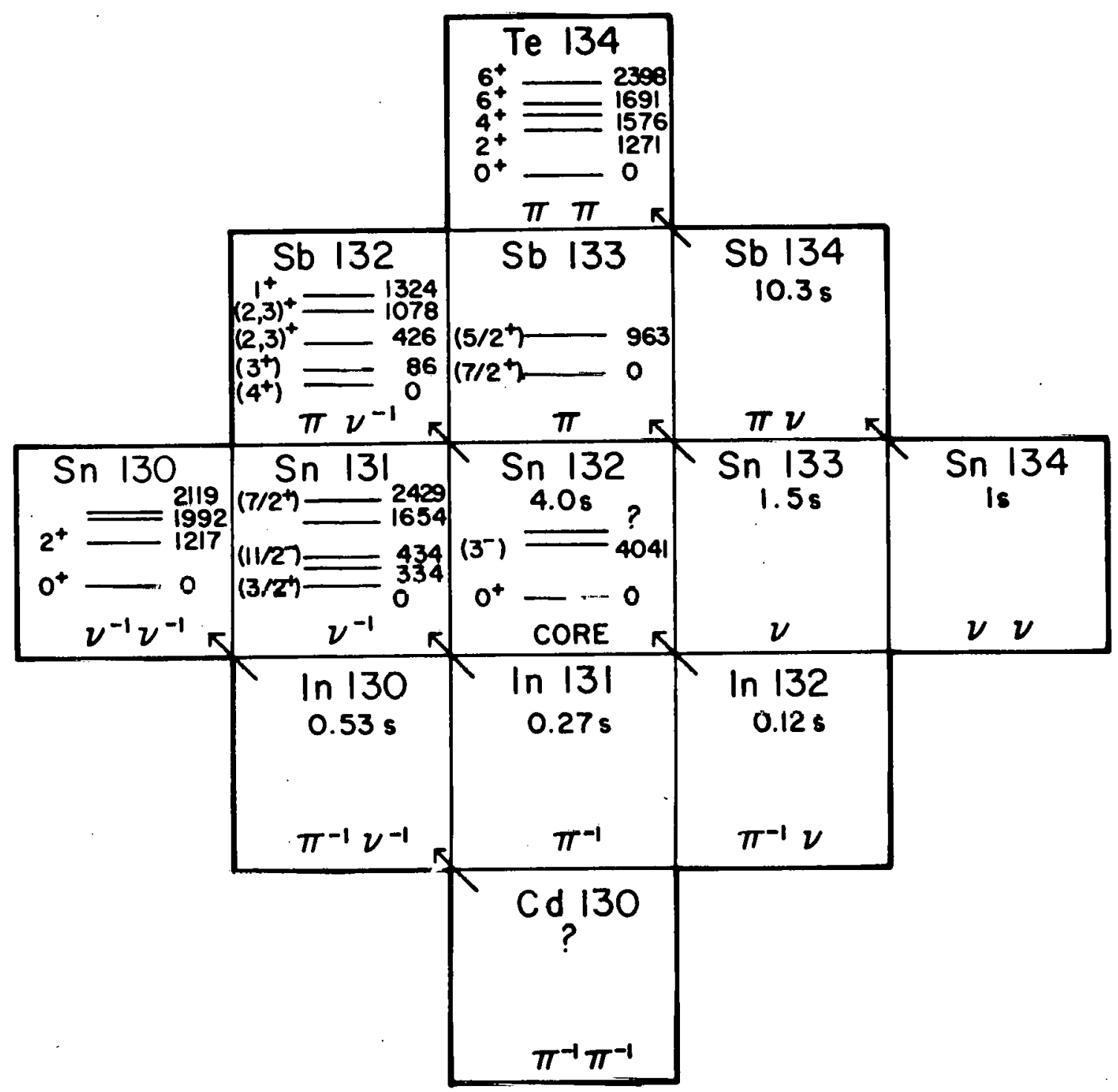

Fig. 25: The nuclide chart near doubly-mag1c ${ }^{132} \mathrm{Sn}$. 
determined by $\beta$ decay experiments and also the $T_{1 / 2}$ 's of their parents if known.

It is of great interest to determine to what degree the nucleus ${ }^{1.32} \mathrm{Sn}$ is doubly-magic. In particular the location and character of the core excited states in the nuclel in Fig. 25 would shed much light on this question. The only core states known from $\beta$ decay are the two in ${ }^{132} \mathrm{Sn}$. Due to the large $Q_{B}$ 's available it should be posstble to excite core states in ${ }^{132} \mathrm{Sn}$ (core), ${ }^{133} \mathrm{Sb}$ (core + proton), and ${ }^{131} \mathrm{Sn}$ (core + neutron hole) if detailed decay studies with very good statistics are carried out. Most of the core states are probably above $3 \mathrm{MeV}$ so their corresponding $\beta$ feedings would be weak. Another indication of the degree to which a region is doubly-magic is the accuracy with which shell model calculations involving only extra-core particles can describe levels up to several MeV. Two, three, and four valence nuclei such as ${ }^{128} \mathrm{Sn},{ }^{129} \mathrm{Sn},{ }^{130} \mathrm{Sn},{ }^{134} \mathrm{Te},{ }^{135} \mathrm{I}$, and ${ }^{136} \mathrm{Xe}$ are good test nuclei ${ }^{19}$ for this purpose. ${ }^{136} \mathrm{Xe}$ has been studied at TRISTAN I and preliminary results on ${ }^{128} \mathrm{Sn}$ are given above. With TRSITAN II it should be possible

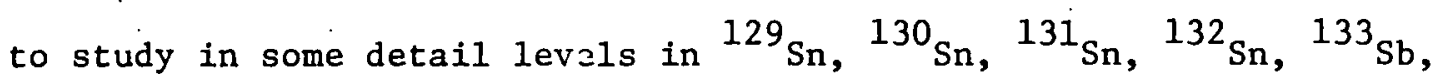
${ }^{1.34} \mathrm{Te}$, and ${ }^{135} \mathrm{I}$. The decay of ${ }^{132} \mathrm{Sn}$ to levels in ${ }^{132} \mathrm{Sb}$ is well characterized. Study of levels in ${ }^{134} \mathrm{Sb}$ from the decay of ${ }^{134} \mathrm{Sn}$ should be possible if the holdup time for $\mathrm{Sn}$ in the fon source is not too long. Because of low yields studies of levels in ${ }^{130} \mathrm{In},{ }^{131} \mathrm{In},{ }^{132} \mathrm{In}$ and ${ }^{130} \mathrm{Cd}$ are probably not feasible with fission sources.

\section{ACKNOWLEDGMENTS}

The success of TRISTAN II was due to the efforts of many people. W. L. Talbert, Jr., F. K. Wohn, A. R. Landill, and R. G. Serusss were 
responsible for the design of the in-beam ion source. A. R. Landin, R. L. Gill, D. R. Lekwa, and M. A. Cullison kept the system in running order and the data was taken and analyzed by M. L. Gartner, D. R. Margetan, R. L. Gill, T. K. Li, and L. L. Shih. 


\section{REFERENCES}

1. W. L. TALBERT, JR., "TRISTAN I Techniques, Capabilities, and Accomplishments," in proceedings of Ames-BNL Workshop on ISOL Systems, to be published.

2. G. RUDSTAM, Nuc1. Instrum. Methods 139, 239 (1976).

3. F. K. WOHN, "TRISTAN II - Extension of Capabilities to Non-Gaseous Fission Products," in proceedings of Ames-BNL Workshop on ISOL Systems, to be published.

4. P. ARMBRUSTER, Proc. 3rd Internat. Conf. on Nuclei Far from Stability, Cargese, 1976 , p. 3.

T. A. KHAN, "Nuclear Structure Studies at JOSEF," in proceedings of Ames-BNL Workshop on ISOL Systems, to be published.

5. W. R. WESTERN, JOHN C. HILL, W. C. SHICK, JR., AND W. L. TALBERT, Jr., Phys. Rev. C 14, 275 (1976).

6. D. R. MARGETAN, JUHN C. HILL, S. A. WILLIAMS, and W. L. TALBERT, JR., Bul1. Amer. Phys. Soc. 22, 594 (1977).

7. J. C. WELLS, JR., JOHN C. HILL, R. L. GILL, S. A. WILLIAMS, and W. L. TALBERT, JR., Bull. Amer. Phys. Soc. 21, 995 (1976).

8. T. K. LI, L. L. SHIH, and JOHN C. HILL, Bull. Amer. Phys. Soc. 22, 1025 (1977) .

9. S. T. HSUE, H. H. HSU, F. K. WOHN, W. R. WESTERN, and S. A. WILLIAMS, Phys. Rev. C $\underline{12}, 582$ (1975).

10. H. H. HSU, S. A. WILliaMS, F. K. WOHN, and F. J. MARGETAN, Phys. Rev. C $\underline{16}, 1626$ (1977).

11. S. A. WILLIAMS, "Collective Structure of Medium-Mass Nuclei," in proceedings of $\Lambda$ mes-DNL Wurkshop on LOL Systems, to be published. 
12. K. FRITZE and K. GRIFFITHS, Radiochim. Acta I, 59 (1967).

13. B. Fogelberg, A. BACKLIN, and T. NAGARAJAN, Phys. Lett. 36B, 334 (1971).

14. K. ALEKLETT, Thesis, Chalmers University of Technology, Goteborg, Sweden, 1977.

15. JOHN C. HILL, M. L. GARTNER, T. K. LI, and W. L. TALBERT, JR., Bull. Amer. Phys. Soc., 22, 595 (1977).

16. M: L. GARTNER, JOHN C. HILl, and T. K. LI, Bull. Amer. Phys. Soc., 22, 595 (1977).

17. R. L. GILL, JOHN C. HILL, and A. F. VOIGT, Bu11. Amer. Phys. Soc., 22, 595 (1977).

18. M. L. GARTNER and JOHN C. HILL, Bull. Amer. Phys. Soc. 22, 1028 (1977).

19. W. J. BALDRIDGE, Phys. Rev. C, to be published.

J, P. VARY, "Nuclear-She11 Theory Near Doubly-Magic ${ }^{132} \mathrm{Sn}, "$ in proceedings of Ames-BNL Workshop on ISOL Systems, to be published. 
DISTRIBUTION LIST

J. C. Hill 50

USDOE-TIC

Ames Laboratory Library $\underline{13}$

90

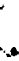

